\title{
Landslide risk management analysis on expansive residential areas - case study of La Marina (Alicante, Spain)
}

\author{
Isidro Cantarino ${ }^{1}$, Miguel Angel Carrion ${ }^{1}$, Jose Sergio Palencia-Jimenez ${ }^{2}$, and Víctor Martínez-Ibáñez ${ }^{1}$ \\ ${ }^{1}$ Department of Geological and Geotechnical Engineering, Universitat Politècnica de València, \\ Camino de Vera, s/n, 46071, Valencia, Spain \\ ${ }^{2}$ Department of Urban Planning, Universitat Politècnica de València, Camino de Vera, s/n, 46071, Valencia, Spain
}

Correspondence: Víctor Martínez-Ibáñez (vicmarib@trr.upv.es)

Received: 26 June 2020 - Discussion started: 5 August 2020

Revised: 16 April 2021 - Accepted: 28 April 2021 - Published: 15 June 2021

\begin{abstract}
Urban expansion is a phenomenon that has been observed since the mid-20th century in more developed regions. One aspect of it is the urban development of holiday resorts with second homes that generally appeared following world political stabilisation. This residential expansion has often happened with scarce control, especially in its early stages, allowing areas to be occupied that are not so suitable in terms of the environment, culture and landscape, not to mention the very geological risks of flooding, earthquakes and landslides. Indeed, the risk of landslides for buildings occupying land in zones at such risk is not a matter solely attributable to the geomorphological characteristics of the land itself, nor is it simply a question of chance; it is also due to its management of such land, generally because of a lack of specific regulations. This study aims to lay down objective criteria to find how suitable a specific local entity's risk management is by looking at the evolution of its urban development procedures. It also aims to determine what causes the incidence of landslide risk (geomorphology, chance, land management, etc.) and finally to suggest control tools for the public bodies tasked with monitoring such matters.
\end{abstract}

\section{Introduction}

Landslide risk evaluation, management and mitigation are aspects that have been dealt with profusely in recent decades in the literature specialising in such matters. There is a multitude of studies on these matters, notably the summary put forward by Dai et al. (2002) with a critical review of landslide research and the strategies for reducing damages and losses, as well as the relevant publications by Lee and Jones (2004) and Glade et al. (2005) with a multidisciplinary perspective on landslide management. The recent review of quantitative methods for analysing landslide risk by Corominas et al. (2014) is also very noteworthy.

It is important to consider that the risk associated with landslides is changing as a consequence of environmental change and social developments. Climate change, the increased susceptibility of surface soil to instability, anthropogenic activities, growing (and uncontrolled) urban development and changes in land use with increased vulnerability for the population and infrastructure as a result all contribute to the change - and in most cases the increase - in the risk of landslides (Gallina et al., 2016).

Urban expansion is a phenomenon associated with an increase in living standards and improvement in transport, communication and services outside the traditional population hubs. Among the many aspects of this phenomenon being studied, there is one that stands out as absolutely essential: the organisation and regulation of this urban growth. Indeed, in the classic work by De Terán (1982), the desired approach to urban planning is described as the need to establish order in developing it, in view of the damage and inconveniences caused by spontaneous urban development.

It is clear that urban expansion using unsuitable planning aggravates the incidence of geological risks. Specifically, landslides are one of the most dangerous natural disasters in terms of their frequency and the seriousness of the damage they do, leading to loss of human life and social infrastructure in practically the whole world, which has been increas- 
ing in recent decades (Lee et al., 2017; Sandić et al., 2017; Cascini et al., 2005).

One of the main causes that explain the rise in geological risks in residential areas is expansive urban development processes, with a growing trend observed in these risks on a global scale, especially as regards landslides (Zhou and Zhao, 2013). These expansionary activities have significantly increased the pressure on the land and consequently its effect on the population due to the occupation of land unsuitable for residential buildings (Fernández et al., 2016). This situation indicates improper management of the land, caused by a lack of suitable zoning of risks that hinders good planning for the use of the land (Cascini et al., 2005; and Cascini, 2008).

In other words, residential land usage may be exposed to greater natural risks precisely because such phenomena are not included in urban planning. When such planning is properly applied, it may help reduce exposure to the risk within urban areas. Indeed, it is considered to be a powerful tool in helping efficient, equitable adaptation between land occupation and natural risks (Hamma and Petrişor, 2018; Macintosh, 2013). There is a plethora of references that agree on the link between landslides and urban development. In some cases, there are rules on uses in said circumstances, but they have not been taken into account, thereby allowing for illegal and irregular occupation, as happened in the region of Campagna, Italy (Di Martire et al., 2012). In other cases, the course of rivers has been changed as a result of an increase in urban land, leading to negative effects on landslides as seen on the coast of Genoa (Faccini et al., 2015) and the city of Doboj in Bosnia and Herzegovina (Sandić et al., 2017).

The great demand for residential land to develop tourism in particular has caused similar situations. One example is the case cited by Katsigianni and Pavlos-Marinos (2017) on the Greek island of Santorini. A similar situation is seen in Mengshan, China (Peng and Wang, 2015), where engineering measures have been introduced a posteriori in a mountain tourist resort with a high risk of landslides. So, when drawing up and implementing urban planning, these types of factors must be taken into account amongst many others in order to suitably regulate the territory and prevent disorganised urban sprawl.

Faced with this situation, which has been widely recognised around the world, there is a need for risk governance to be duly included in urban planning (Renn and Klinke, 2013), improving the resilience of urban developments implemented and their possible growth (Zhai et al., 2015). It is also necessary to carry out suitable zoning of the risks to help reduce disasters (Wang et al., 2008). The great challenge is faced precisely in applying urban governance, attempting to define effective systems and tools adapted to the new context of natural risks (Birkmann et al., 2014). Some experiences have shown the need to include the population's participation in tackling this problem, encouraging the adoption of solutions and management of them, as mentioned by Gough (2000) in New Zealand.
For all these reasons, it is surprising that the effectiveness and results of management of zones exposed to landslide risk have received less attention. In the end, it is not only necessary to know how to quantify and locate the risks, as well as to put forward steps to avoid or mitigate them, but also to lay down procedures that can determine whether the management by technicians and politicians is effective and if the risk has truly been mitigated.

Thus, the main goal of this work is to determine whether the pace at which zones at risk are being occupied has a point of inflection where it begins to steadily decrease. This point of inflection should be the result of a comprehensive application of specific regulations for the land that hinder or restrict residential construction in that type of area. It is along these lines that this paper suggests control tools for the public bodies tasked with monitoring such matters.

Another significant aim of this work should also be noted: this involves differentiating correct management of the terrain (specifically addressing its occupation by residential housing) from management that can clearly be improved. In particular, considering the risk of landslides for residential housing, the possibility of said risk becoming stabilised is studied over the time series. In this case, the management can be deemed adequate.

Nevertheless, if the risk increases over time, then it can be attributed to improper management, which should be corrected. The aims of this work also include analysing this situation, as well as determining what causes an increase in landslide risk, for example by considering geomorphological dynamics, inadequate land management and even bad luck.

To ascertain the importance of these control tools, a case on the Mediterranean coast has been studied in this work. Significant construction of new buildings has sprawled along said coastline, flouting planning regulations and thus proving the complete inefficiency of such regulations in containing this phenomenon (Malvárez et al., 2003). That is why it is essential to enforce the government regulations developed, as well as to activate pertinent control mechanisms to ensure compliance.

\section{General methodology}

\subsection{Objectives}

Given the background described above, it is necessary to determine the extent to which residential areas are at risk of landslides, to understand the causes of these risks and to improve the planning for them. The basis for this should be a study of the behaviour of the risk taken upon building them and the factors determining it. To do so, it is necessary to begin with a map of the risk distribution and the annual residential construction data in a long time series. By knowing this risk and construction data, one can estimate its progress over time and whether a greater or lesser relative risk is be- 
ing taken. Specifically, it is understood that this evolution in risk must not be exclusively a matter of the land's orographic characteristics, or even of chance, but it should also be greatly influenced by the pertinent territorial management.

The first task to be carried out is to gather residential building data as an annual summary for each local entity into which the zone of study is divided. Studying temporal series can then provide a lot of dynamic information about the evolution of a set of data. The series do not have to follow constant growth patterns since, as will be seen, they may undergo seasonal and other changes. This happens especially in the main data series to be analysed, which is the evolution of residential construction over time. Of course, it is also affected by the vagaries of big economic cycles, but such supra-annual seasonality is not going to be studied in depth.

The second dataset must arise from the geolocalised map of risk distribution. Normally, this is based on a landslide susceptibility map (LSM) that has been deemed stable during the period analysed. Indeed, the risk map is calculated based on the temporal nature of construction and must be approximately in sync with this process. Moreover, the occurrence of a landslide is generally linked to trigger mechanisms that respond to events subject to a specific return period. The probability calculation also uses feedback from the appearance of these events, whose frequency is being modified as a result of climate change. However, according to Gariano and Guzzetti (2016), the effects of climate change on the type, extent, magnitude and direction of the changes in the slopes' stability conditions, as well as on the location, abundance and frequency of the landslides, are not completely clear. In the end, climate change is not going to be taken into account specifically in this work.

The main goal of this research is to seek risk modification patterns throughout a time series in local entities (hereinafter referred to as urban administrative divisions, UADs). Three main, non-exclusive hypotheses are proposed that enable the causes of the evolution in risk to be explained via a specific line of reasoning:

1. random reason, with no clear reason explaining the phenomenon;

2. geomorphological land characteristics: slope, lithology, land cover, etc.; and

3. management by local or regional public bodies responsible for land planning.

Simple observation of the annual evolution of risk in a specific zone is not by itself very conclusive in determining whether it is due to one of the causes described above. The trend has to be connected to the evolution of construction, verifying the temporal correlation between the two series within a local entity and among neighbouring local entities. This aspect will be analysed in the section dealing with the evolution of risk.
In keeping with the objectives described, it is necessary to have two fundamental types of georeferenced data: the data on residential construction evolving over time and the data concerning the risk as a result of occupying the land, with the risk's distribution over time being variable depending on the pace of construction.

Logically, it is necessary to have data on the residential plots or parcels, specifically the data on the built-up area of each residential parcel (as "gross floor area", hereinafter GFA), year of construction and geographic location. These types of data are beginning to be easily obtainable in some countries thanks to the development of public access digital cadastres (USA, Australia, France, Germany and others), which also appear to be near completion in many others. Currently, such data in Spain can be downloaded sequentially by municipalities via the Spanish Cadastral Agency (DGC).

\subsection{Risk evaluation}

The quantitative risk evaluation is to be carried out by applying the known general equation of risk (Eq. 1), which includes the terms hazard or probability, elements affected and their value (exposure), and the seriousness of the damage (vulnerability), based on the classic definitions from the Office of the United Nations Disaster Relief Organization (UNDRO, 1979).

Risk $=$ hazard $\times$ exposure $\times$ vulnerability

The value of risk is generally calculated in monetary units (EUR), though other types of unit may also be used (builtup $\mathrm{m}^{2}$, casualties, etc.). In this work, the type of risk analysed is economic loss due to landslide damage to residential buildings.

\section{Hazard}

This is the probability of occurrence of a potentially damaging natural phenomenon such as a landslide within a specific period of time in a specific area. Calculation of this is normally based on a susceptibility map. Specifically, for each level of susceptibility the hazard must be calculated in units of probability, for which it is necessary to turn to inventory data of landslides. These two types of probability - temporal and spatial - are in keeping with Eq. (2):

Hazard $=$ Spatial probability $\times$ Temporal probability.

\section{Exposure}

This includes people, property, systems or other elements present in hazard zones that are thereby subject to potential losses. Therefore, exposure indicates the extent to which the elements at risk are actually located in the path of a particular landslide (Corominas et al., 2014). 


\section{Vulnerability}

This is the degree of loss to a given element or set of elements within the area affected by the landslide hazard. It is expressed on a scale of 0 (no loss) to 1 (total loss). Vulnerability is probably the most difficult aspect to assess, due to the complexity and the wide-ranging variety of landslide processes (Glade, 2003). Following a technical/engineering approach, the seriousness of the damage done is a function of the magnitude or intensity of the landslide and the studied building's capacity for resistance.

\subsection{Temporal evolution of risk}

The essential purpose of this work is to define a reliable, simple method that will enable the risk's dynamics to be described. One strategy would be to recognise if the risk taken increases or decreases at the same pace as the construction of residential buildings. It would seem logical that this variation of risk should be estimated not as an absolute value but in relation to the volume of construction at a given time, ascertaining whether there is a temporal correlation between these two variables or not.

An ideal situation pattern can be put forward of working with a long series of at least $40-50$ years, since the beginning of the urban development boom in a specific zone. Three main sections can be found in this series with two different risk management types.

Firstly, let us consider a suitable management type. In the early years of this example situation pattern, there is disorganised construction occupying the most profitable spaces but at the same time in not very suitable areas from the point of view of geological risk and the impact on the environment and the landscape. During the intermediate section, the occupation of zones at risk begins to change pace as urban development legislation begins to appear, along with land planning, environmental awareness, etc. The last section sees a very clear drop in the pace of the risk's growth, as the land regulation restrictions contemplated are directly applied. This theoretical behaviour is shown in Fig. 1.

However, a varying panorama of unsuitable or improvable risk can also be found (Fig. 1). This type of growth in risk can arise when the pressure to build residential housing is so great that spaces that do not have the optimal conditions in terms of location and which until then had maintained their natural characteristics become occupied. Building on such spaces may entail taking greater risks because safer terrains have already been used up. Hence, the great increase in risk in Sect. 3 (Fig. 1, "Improvable management" line) should not be admissible in proper territorial management, and it is thus essential to provide tools to demonstrate such anomalies as shown in this work.

For dynamic analysis of the data shown in Fig. 1, the two main annual data series must be used: one based on the evolution of the residential built-up area and the other on the risk

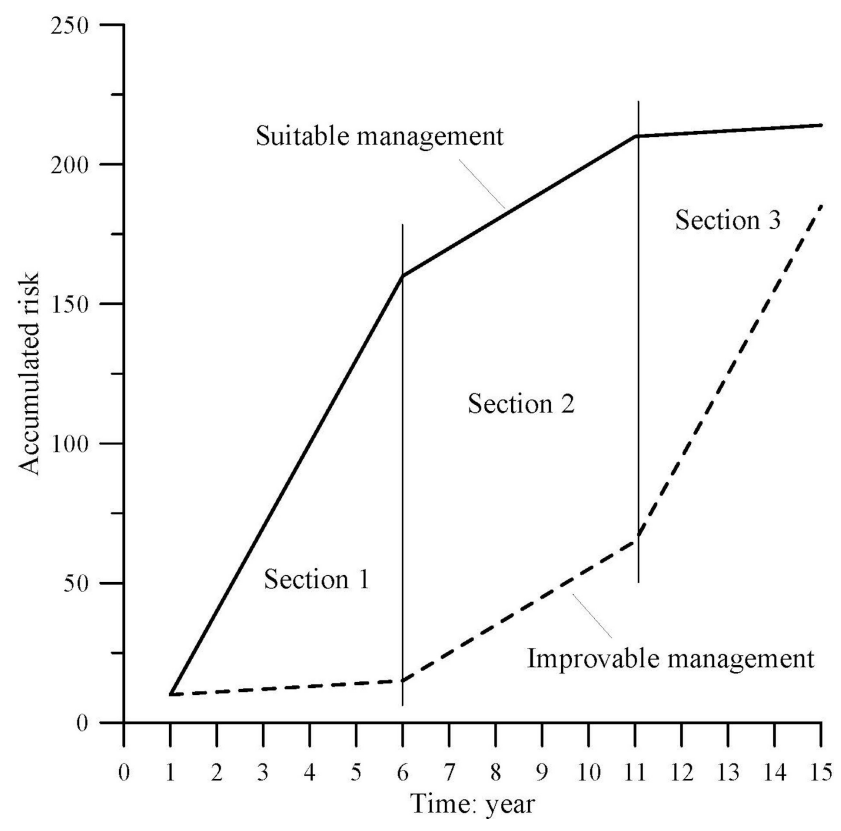

Figure 1. Theoretical evolution of risk accumulated over time for a 1 -year series pattern.

affecting part of that built-up area. The former is the gross floor area (GFA, in $\mathrm{m}^{2}$ ), calculated every year $y$ based on cadastral parcel data $(\mathrm{CP} i)$ by means of Eq. (3):

$\operatorname{GFA}(y)=\sum_{i=1}^{n} \operatorname{GFA}_{(\mathrm{CP}) i}$.

Once the value of $\operatorname{GFA}(y)$ has been obtained, the simple moving average of order 3 for each year $y$, $[\operatorname{MAvGFA}(y)]$, is applied according to Eq. (4):

$\operatorname{MAvGFA}(y)=$ mean GFA $(y-1, y, y+1)$.

Applying the general equation of the risk (see Eq. 1) gives the risk value (RV) in EUR for each cadastral parcel CP affected, in accordance with the susceptibility map (Eq. 5):

$\mathrm{RV}_{\mathrm{CP}}=H_{\mathrm{CP}} \times E_{\mathrm{CP}} \times V_{\mathrm{CP}}$.

Similarly, the simple moving average is calculated for the risk value MAvRV( $y$ ) via Eqs. (6) and (7):

$\mathrm{RV}(y)=\sum_{i=1}^{n} \mathrm{RV}_{(\mathrm{CP}) i}$

$\operatorname{MAvRV}(y)=$ mean $\operatorname{RV}(y-1, y, y+1)$.

A relationship is sought between the two series to explain the trend towards a model of residential construction with increasing, stable or decreasing risk with relation to the builtup area. It is proposed that the relationship between risk and the built-up area should be used as an indicator of the evolution of risk and the construction associated with it. 
Within a specific period of time, in the two moving average series a monotonically increasing interval can be selected that is limited by the years $\left[y_{1}, y_{2}\right]$, where $y_{2}>y_{1}$. Two functions are defined for the risk values and for the built-up area: $f(y)=\operatorname{RV}(y) ; g(y)=\operatorname{GFA}(y)$.

It has been confirmed that the way growth in risk with time directly relates to the pace of construction is determined by the behaviour of the quotient between functions $f(y)$ and $g(y)$. Thus, for example, proposing two growth ratios rRV and rGFA during the chosen period, which are approximately constant and where rRV > rGFA, it is easily shown that the quotient function is growing. In the opposite case, $\mathrm{rRV}<\mathrm{rGFA}$, the quotient function is falling.

The adimensional (relative) risk ratio (RR) between years $y_{1}$ and $y_{2}$ is defined in the following Eq. (8):

$\operatorname{RR}\left(y_{2}, y_{1}\right)=\frac{\frac{\mathrm{RV}\left(y_{2}\right)}{\operatorname{RV}\left(y_{1}\right)}}{\frac{\mathrm{GFA}\left(y_{2}\right)}{\operatorname{GFA}\left(y_{1}\right)}}=\frac{\mathrm{rRV}}{\mathrm{rGFA}}$.

To sum up, it is concluded that $f(y) / g(y)$ is a function whose growth slope is defined by the risk ratio value (RR) for the chosen interval $\left[y_{1}, y_{2}\right]$. The different options are summed up in Table 1.

It is preferable to use the absolute values from the relationship between RV and GFA in order to be able to compare their magnitudes between the different municipalities. In addition, working with functions of accumulated values $\mathrm{RV}_{\text {acc }}$ and $\mathrm{GFA}_{\mathrm{acc}}$, it is ensured that the two base curves are monotonically increasing for the entire period being studied. It is easily demonstrated that the quotient function of the accumulated series $\mathrm{RV}_{\mathrm{acc}} / \mathrm{GFAa}_{\mathrm{acc}}$ also meets the characteristics determined for the RR value in Table 1 .

These annual values can be transferred to a graph showing the resulting curve in order to analyse its ascending or descending trend (Fig. 2).

Equation (9) shows the calculation of the accumulated RR values for each year:

$\mathrm{RR}(y)=\frac{\mathrm{RV}_{\mathrm{acc}}}{\mathrm{GFA}_{\mathrm{acc}}}=\frac{\sum_{i=y_{0}}^{y} \mathrm{RV} i}{\sum_{i=y_{0}}^{y} \mathrm{GFA} i}$.

This equation is applied for the entire time series available, always starting from an original year $y_{0}$.

In these quotient functions, a simple deterministic trend is going to be assumed. Two specific indicators can be extracted from these functions. The first of these would be to calculate the trend of the curve RR(y) simply by means of Eq. (10), which gives the slope of the straight line $m$ that joins the two points of the curve RR $(y)$ between moments $s$ and $t$ with periods of $n$ years.

$$
\begin{aligned}
& \operatorname{mRR}(t, s) \\
& \quad=\frac{[\text { mean }(\text { RRt...RRt }+n)-\text { mean }(\text { RRs. ..RRs }+n)]}{(t-s)}, \\
& \forall t>s
\end{aligned}
$$

These reference points should be located in the temporal series at the moments prior to and after decisive changes in land management policy. It can also be used at the start of the series in order to learn the behaviour of risk in the early years of residential expansion.

Within the analysis of the temporal series of risk, it is worth noting that it may also be important to study the synchronisation of their peaks to explain certain types of behaviour. Firstly, this may be done among the different geographically neighbouring local entities. For example, a specific type of municipal management would stand out if big differences are found with the neighbouring entity, especially if their geomorphological characteristics are very similar. To do so, three causes can be put forward to explain an external temporal correlation among neighbours, which fit with the hypotheses put forward in Sect. 2.1:

1. With a total lack of synchronisation and without demonstrating behavioural patterns, the cause must occur randomly as a result of not very notable effects that cannot be analysed globally.

2. With synchronisation among neighbouring entities, the cause must be due to geomorphological characteristics of the terrain, since they are autocorrelated by geographic proximity.

3. With differing synchronisation in nearby areas but with certain patterns of behaviour in wider areas, the cause must be sought in the different ways of managing the land.

Secondly, the internal synchronisation of construction peaks with the risk peaks for the same local entity should coincide in time under theoretical conditions. However, another two situations may also occur, which show that the construction and risk assumed are not necessarily governed by logic. Their possible reasons could be the

1. risk peak brought forward - buildings with a greater level of risk may be of greater commercial interest (e.g. due to dominant locations with the best views) and are thus built sooner;

2. risk peak delayed - suitable parcels begin to become scarce after a period of intense building activity, so that the last buildings are in a worse location and thus a greater risk is assumed.

A global view of the process is necessary, together with a complete study of the temporal series. It is usually preferable 
Table 1. Characteristics of the risk ratio (RR).

\begin{tabular}{llll}
\hline RR value & Type of curve & Characteristic & Discussion \\
\hline$>1$ & Monotonically increasing & $\begin{array}{l}\text { Growth rate of the risk value greater } \\
\text { than that of the built-up area. }\end{array}$ & $\begin{array}{l}\text { Disproportionate risk growth, without } \\
\text { restrictions or planning. } \\
\text { Unfavourable situation. }\end{array}$ \\
$\approx 1$ & Monotonically constant & $\begin{array}{l}\text { Growth rate of the risk value similar to } \\
\text { that of the built-up area. }\end{array}$ & $\begin{array}{l}\text { No well-defined evolution. } \\
\text { Situation not clearly favourable. }\end{array}$ \\
$<1$ & Monotonically decreasing & $\begin{array}{l}\text { Growth rate of the risk value less than } \\
\text { that of the built-up area }\end{array}$ & $\begin{array}{l}\text { Growth of risk restricted, which must be } \\
\text { due to some type of criterion. } \\
\text { Favourable situation. } \\
\text { This must occur in Sect. 3 of Fig. 1. }\end{array}$ \\
\hline
\end{tabular}

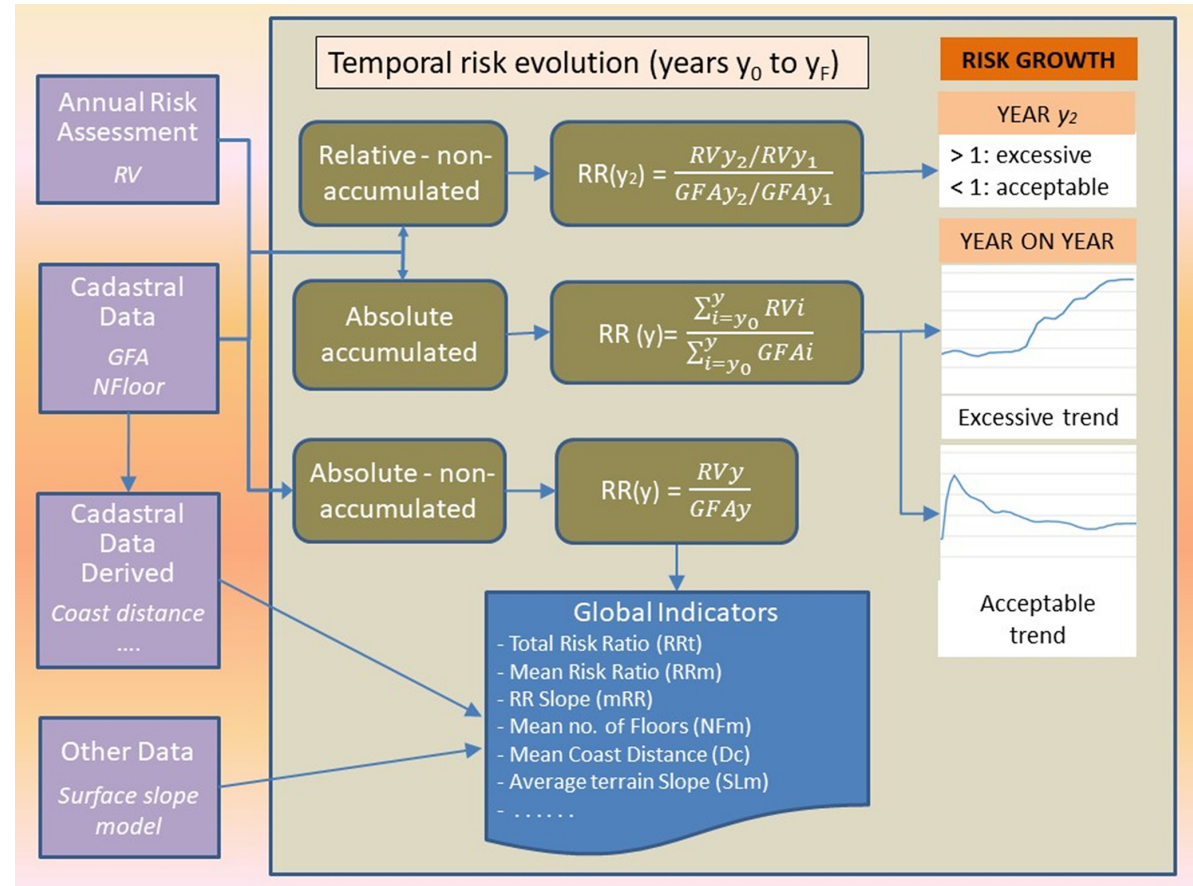

Figure 2. Curve trend of different types of risk ratio.

to summarise it in specific indicators that directly reflect the situation of the comprehensive temporal series for each of the urban administrative divisions (UADs, municipality equivalent) into which the study area is divided.

These indicators enable direct comparisons to be made and analogies and differences to be seen more easily between different UADs. To do so, variables that are not affected by the area of the UADs analysed should be used. One solution is to calculate specific variables distributed homogeneously over the land's area.

The most relevant factor is without a doubt the RR, derived from the quotient function $\mathrm{RR}(\mathrm{y})$, calculated as a summary of the complete series in Eq. (11):

$\mathrm{RRt}=\frac{\sum \mathrm{RV}(\mathrm{EUR})}{\sum \mathrm{GFA}\left(\mathrm{m}^{2}\right)} \times 1000$, where $\Sigma$ GFA and $\Sigma$ RV are total values for the complete period per UAD.

The risk ratio defined in Eq. (11) allows us to know how much risk has been assumed throughout the period under study and to be able to relate it to the other territorial units by specifying if it is greater or lesser than the average for the zone of work. It is thus possible to highlight the units that are assuming an excessive risk.

A summary of other indicators that can be calculated for each UAD is shown in Table 2.

\section{Case study: La Marina}

The work by Cantarino et al. (2014) emphasises that Alicante was the province most affected by landslide risk value on res- 
Table 2. Global indicators per UAD.

\begin{tabular}{|c|c|c|}
\hline Name & Formula & Notes \\
\hline Total risk ratio, RRt (EUR per $1000 \mathrm{~m}^{2}$ of GFA) & $\mathrm{RRt}=\Sigma \mathrm{RV} / \Sigma \mathrm{GFA} \times 1000$ & Already described in the text (Eq. 11). \\
\hline Mean RR, RRm (EUR per $1000 \mathrm{~m}^{2}$ of GFA) & $\mathrm{RRm}=\Sigma \mathrm{RR} / \mathrm{ny}$ & $\begin{array}{l}\text { Less useful as it is an average of aver- } \\
\text { ages. }\end{array}$ \\
\hline Mean no. of floors per CP, NFm & $\mathrm{NFm}=\left(\Sigma\left(\mathrm{GFA} / S_{\mathrm{CP}}\right)\right) /$ ny & $\begin{array}{l}\text { Interesting to know the type of build- } \\
\text { ings in the UAD. }\end{array}$ \\
\hline Mean no. of floors in CP affected by risk, NFmr & $\mathrm{NFmr}=\left(\Sigma\left(\mathrm{GFAr} / S_{\mathrm{CP}}\right)\right) /$ ny & $\begin{array}{l}\text { Interesting to know the type of build- } \\
\text { ings affected in the UAD. }\end{array}$ \\
\hline $\begin{array}{l}\text { Mean distance from the CP to the UAD's historical cen- } \\
\text { tre in a straight line, Dhc (m) }\end{array}$ & $\mathrm{Dhc}=(\Sigma \mathrm{Dhc}(\mathrm{CP} i)) / \mathrm{nCP}$ & $\begin{array}{l}\text { Quantifies the importance of the resi- } \\
\text { dential expansion. }\end{array}$ \\
\hline $\begin{array}{l}\text { Mean distance from } \mathrm{CP} \text { to the coast in a straight line, } \\
\mathrm{Dc}(\mathrm{m})\end{array}$ & $\mathrm{Dc}=(\Sigma \mathrm{Dc}(\mathrm{CP} i)) / \mathrm{nCP}$ & $\begin{array}{l}\text { Establishes the proximity of the UAD to } \\
\text { the sea. }\end{array}$ \\
\hline Average slope of the UAD, SLm $\left(^{\circ}\right)$ & $\begin{array}{l}\text { SLm }=\text { mean Slope cells } \\
(5 \times 5 \mathrm{~m})(\text { GIS calculated })\end{array}$ & $\begin{array}{l}\text { Indicates the type of profile (mountain- } \\
\text { ous, flat, etc.). }\end{array}$ \\
\hline $\begin{array}{l}\text { Built-up area per unit of surface area, SpGFA }\left(\mathrm{m}^{2} \text { of }\right. \\
\text { GFA per } \mathrm{km}^{2} \text { of UAD) }\end{array}$ & $\mathrm{SpGFA}=\mathrm{GFA} / S_{\mathrm{UAD}}$ & $\begin{array}{l}\text { Rate or intensity of residential construc- } \\
\text { tion for the total of the UAD. }\end{array}$ \\
\hline $\begin{array}{l}\text { Risk per unit of surface area, SpRV }\left(E^{2} \mathrm{~km}^{-2} \text { of }\right. \\
\text { UAD) }\end{array}$ & $\mathrm{SpRV}=\mathrm{RV} / S_{\mathrm{UAD}}$ & $\begin{array}{l}\text { Rate or intensity of risk (specific risk) } \\
\text { for the total of the UAD. }\end{array}$ \\
\hline Slope of the straight trend line, $\operatorname{mRR}\left(^{\circ}\right)$ & See Eq. (10) & $\begin{array}{l}\text { Determines the trend of the RR value in } \\
\text { a specific period. }\end{array}$ \\
\hline
\end{tabular}

CP: cadastral parcel; $S_{\mathrm{CP}}$ : surface area of the CP (GIS calculated); nCP: number of CPs; ny: number of years in the series; $S_{\mathrm{UAD}}=$ urban administrative division surface area $\left(\mathrm{km}^{2}\right)$.

idential buildings in the Valencia Community region (Spain), with more than EUR 1 million in 2005 and 2009 each. This is chiefly due to the coastal zones in the north-west of the province (La Marina administrative division) with a high demand for housing, which is an area susceptible to higher landslide risks.

Thus, the area selected for this study is located in this area of Alicante (south-eastern Spain) bordering the Mediterranean Sea (Fig. 3). The area includes 50 municipalities, covers $1335 \mathrm{~km}^{2}$ and has a population of 201442 inhabitants according to the 2011 census (Spanish National Institute of Statistics, INE). This population has seen a notable increase since the 1990s (over $50 \%$ ) basically due to tourist activity, though today it has fallen to 171826 inhabitants in the last census (INE, 2018) as a result of the economic crisis. It is a populated mountainous environment rising from sea level to around $1500 \mathrm{~m}$. Its profile is shaped by its proximity to the sea, with a river system that deeply dissects the territory.

La Marina is located in the province of Alicante, which is the Valencia Community region's province with the highest landslide rate per unit of surface area (Hervás, 2017). Its extensive mountainous orography reaches the coastal strip itself, which is not free from risk. This situation is aggravated by being highly attractive for tourism and its residential occupation.

This territory is typical of urban expansion around the Mediterranean basin, which is becoming increasingly intensive and no longer necessarily fostered or supported by the main coastal cities (EEA, 2006). It is an example of the so- called "rural sprawl" generated by second homes for the local population (in some cases first homes too) and of "residential tourism" for people from northern Europe, who spend long periods on the Mediterranean coast. Although initially there was a move towards recovery and restoration of traditional rural constructions, strong demand has led to a proliferation of new-build housing units (Pardo-García and MéridaRodríguez, 2018).

\subsection{Data used}

\section{Basic mapping}

The official maps from the Spanish National Geographic Institute (IGN) provided the borders and areas for the municipal territories to calculate the UADs. They also gave the $5 \times 5 \mathrm{~m}$ DEM (digital elevation model) to calculate the mean slope of each municipality.

\section{Landslide database}

The national Spanish database for landslides BD-MOVES from the Geological and Mining Institute of Spain (IGME) was used, which follows the INSPIRE regulations (Infrastructure for Spatial Information in the European Community). BD-MOVES, created in 2014, is made up of two blocks or sets of georeferenced spatial information: one referring to the description of the intrinsic, relatively invariable characteristics of landslides, and another referring to different ac- 


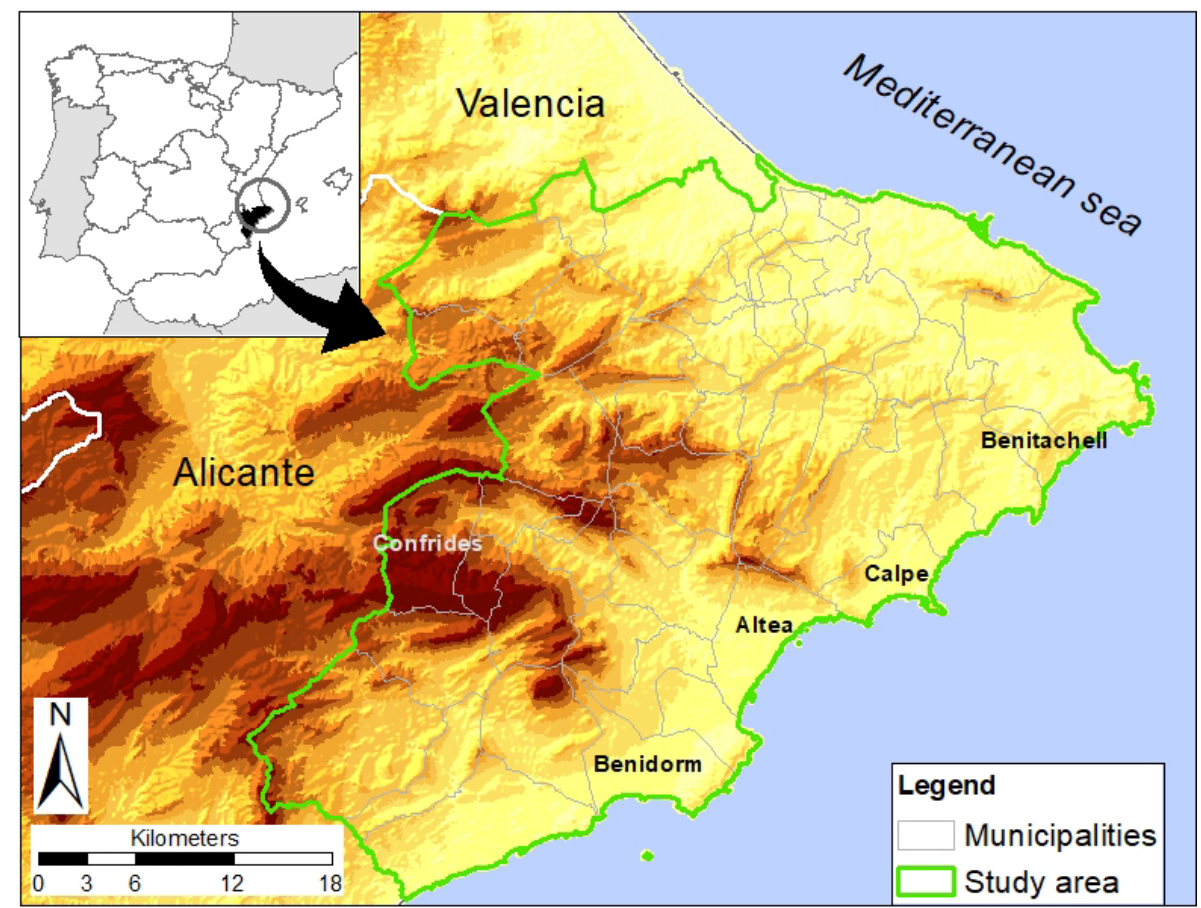

Figure 3. La Marina area. Location of some municipalities mentioned in the text.

tivity events that led to said landslides, including morphometrics, triggering factors, damage and other data.

The other source of data is the landslide map to $1: 50000$ scale in vector format drawn up by the Valencia government's Regional Department of Public Works in the project entitled "Lithology, exploitation of industrial rocks and landslide risk in the Valencia Community" (COPUT, 1998). This map uses geological and geotechnical data from the IGME, $1: 50000$-scale topographical maps and aerial photographs available at that time.

\section{Cadastral parcels}

The information referring to cadastral plots or parcels was obtained from the cadastral mapping available from the DGC according to European INSPIRE guidelines. This cadastral information is provided by interoperable services (WMS and WFS) and can be downloaded in three datasets: cadastral parcels, buildings and addresses. For this study, the former has been chosen because it contains the main item defining the building. Within this item, we can find the data necessary for each parcel: built-up area (GFA), year of construction and type of usage. Only functional and residential parcels have been used for the series 1960-2017.

\section{Classes of susceptibility to landslides}

To calculate the level of hazard, the starting point was the landslide susceptibility map (LSM) drawn up in a previous study (Cantarino et al., 2019). Its characteristics are pixels of $25 \times 25 \mathrm{~m}$ as the unit of surface area and the spatialmulticriteria method (SCME) to weight the factors for obtaining the susceptibility values. The three significant factors used were slope gradient, lithology and land cover.

Specifically, the thresholds of susceptibility classes defined by Cantarino et al. were used. These thresholds were obtained by means of objective, meticulous classification based on a ROC (receiver operating characteristic) analysis, which uses the intrinsic variability of the data and is one of the first applications of this type of map. For this study, the spatial probability for each class has been determined by comparing these susceptible areas with the ones indicated in the inventory. This information, together with the temporal probability, has enabled the hazard and finally the risk to be calculated.

Table 3 shows the susceptibility levels established via the susceptibility indices (LSIs) that define them, together with the number of pixels affected.

Figure 4 with some data used is attached, indicating the three highest levels of susceptibility, together with the location of landslides according to the Spanish Geological Survey (BD-MOVES) and the areas with instabilities according to the Valencia regional government (COPUT). 


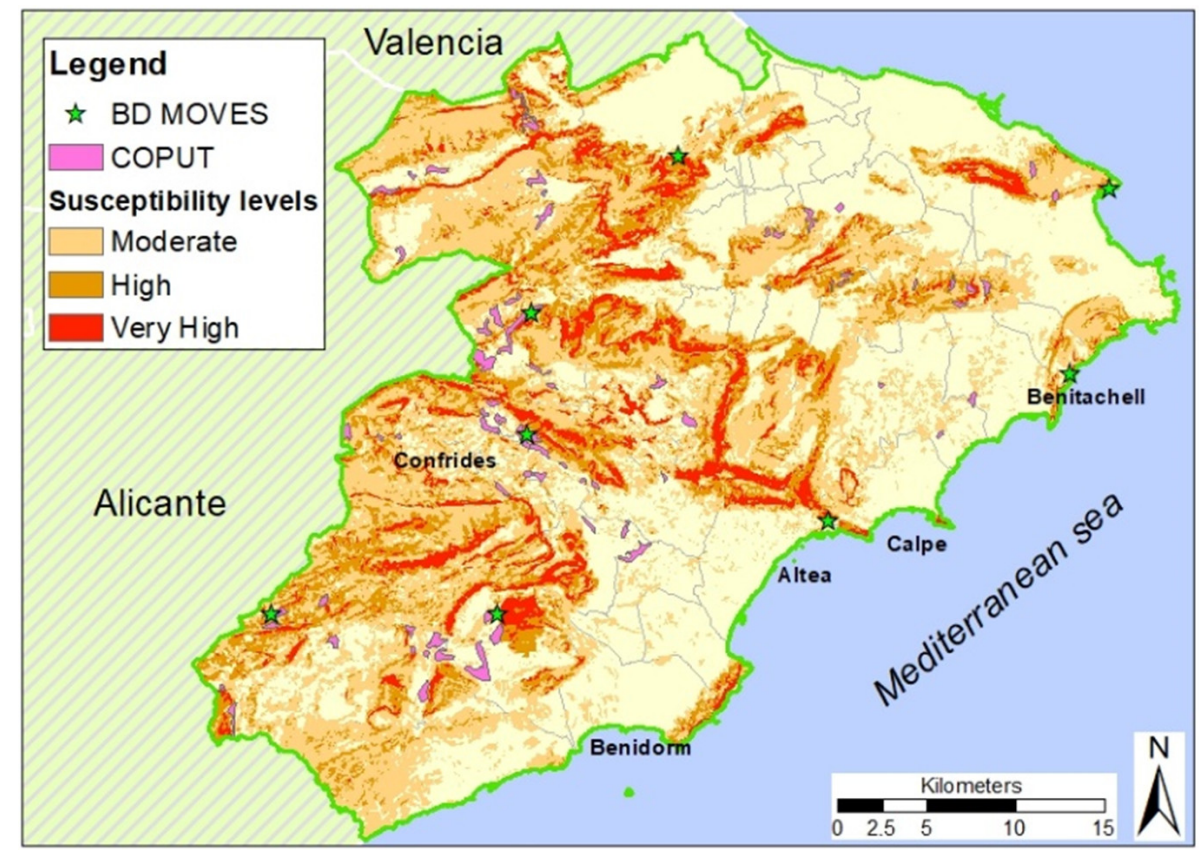

Figure 4. La Marina area. Susceptibility, landslides location and areas with instabilities.

Table 3. Land susceptibility index (LSI) values for the classes under consideration

\begin{tabular}{llrr}
\hline Class & Level & LSI interval & No. of pixels \\
\hline 1 & Very low & $10-35$ & 526777 \\
2 & Low & $35-60$ & 359376 \\
3 & Medium & $60-95$ & 692863 \\
4 & High & $95-149$ & 350051 \\
5 & Very high & $149-340$ & 201170 \\
\hline TOTAL & & & 2130237 \\
\hline
\end{tabular}

Source: Cantarino et al. (2019)

\subsection{Implementation of the method}

Figure 5 shows the flow chart indicating the method followed, which is explained in the above sections. It involves analysing the evolution over time of the residential parcel areas and landslide risks assumed in the urban expansion period in the La Marina area of Alicante province, from 1960 to 2017. Within this interval, a period of intense construction activity can be seen between 2000 and 2008 , followed by a period of slowdown caused by the general economic crisis that occurred at the end of the decade of 2000 and which has not yet clearly ended.

Following the method described, firstly the cadastral parcels with their built-up gross floor area (GFA) were analysed, and then it was seen how the latter evolved over time together with the surface area affected by landslide risk. The final calculation used 1-year periods to summarise the val- ues dealt with individually for each parcel and as a moving average, MAv of order 3, according to Eqs. (4) and (7).

The process followed for risk evaluation was based on locating the peak value of the three high susceptibility levels (between class 3 and class 5; see Table 3) for each cadastral parcel, affected by a buffer of $20 \mathrm{~m}$ around it. All cadastral parcels of an area of less than $10 \mathrm{~m}^{2}$ were eliminated beforehand. The risk per parcel was then calculated, based on its maximum LSI value.

As previously mentioned, possible changes in some of the factors involved in calculating the risk (such as those due to climate change) are not taken into account. The variation in real risk that may arise due to these changes is considered to be of little significance and therefore does not affect the final results.

By applying the equation to calculate the risk value (RV) shown in Eq. (5) for each cadastral parcel, it is possible to calculate the risk in monetary units (EUR) at the 2018 value. The year of construction is not considered, since in general the value is for the cost of reconstruction at the current value if affected by a landslide.

\section{Hazard}

For the temporal probability in Eq. (2) (see Fell et al., 2008), one has to turn to databases such as BD-MOVES from the IGME, which indicates the landslides and the date. For the spatial probability, work has been done with the COPUT's risk mapping for the zone under study.

In BD-MOVES, 13 landslides over the last 20 years are listed, though 5 of them are small slips. Summarising, it is 


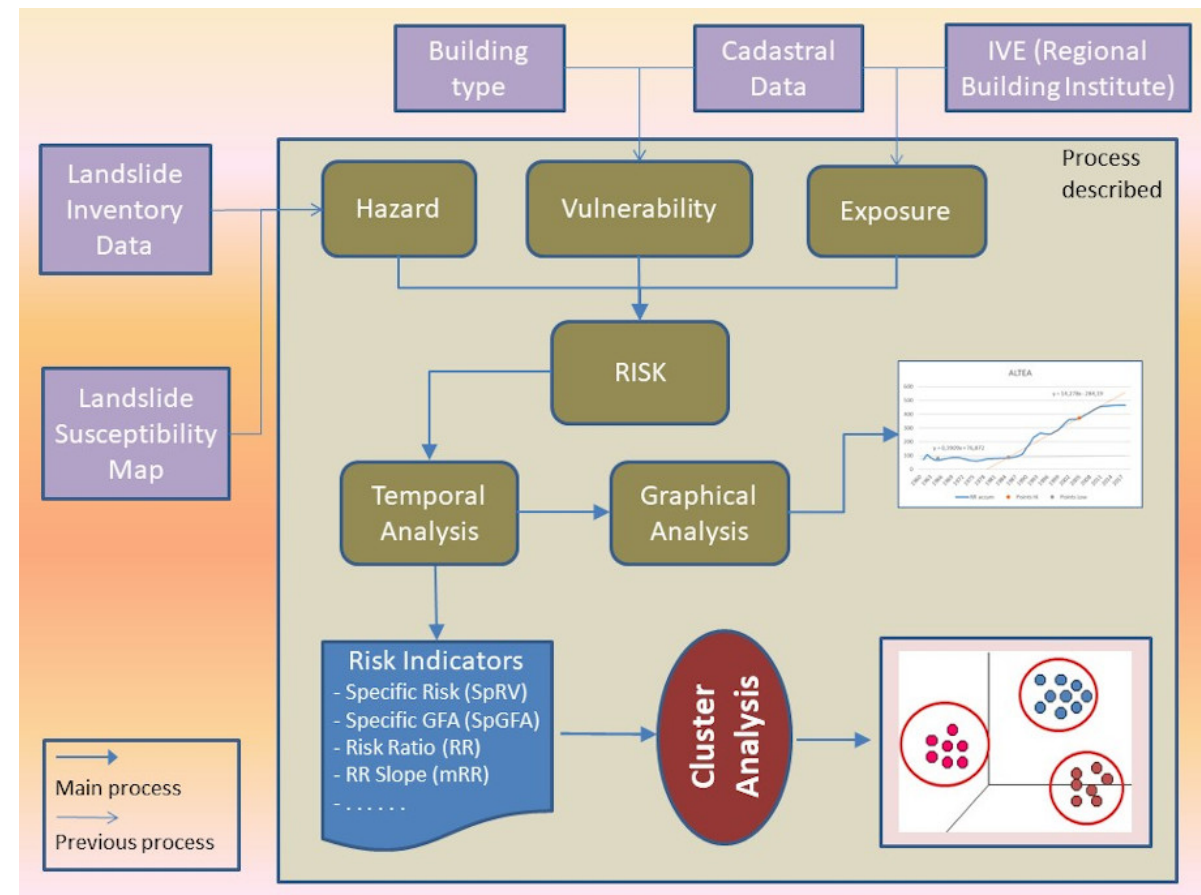

Figure 5. Flow chart of the work procedure.

possible to estimate 8 landslides for this period, with an annual probability $(\mathrm{Pa})$ of $8 / 20$. This annual probability should be adjusted downwards by an adjustment factor of $F_{\mathrm{aj}}$, but this value has been maintained since the inventory is not complete and the landslides that have not been included should be accounted for (Lee, 2009). Said probability was calculated in Eq. (12).

$\mathrm{Pa}=\left(\frac{\text { number of recorded events }}{\text { number of years in the record }}\right) \times F_{\mathrm{aj}}$

To calculate the spatial probability Ps, landslides that appear in COPUT's aforementioned map (1998) were selected, describing their limits and cross-referencing this information with susceptibility levels 3, 4 and 5 of the map listed in Table 3 . The results are shown in Table 4.

Classes 1 and 2 of the susceptibility map (LSM) are not taken into account because they do not show a probability of being affected by risk of landslide. Thus, for each level L of the LSM shown in Table 4, the value of hazard level is obtained using Eq. (13).

$H_{\mathrm{CP}}=f(\operatorname{LSImax})=\frac{S_{\mathrm{RL}}}{S_{\mathrm{L}}} \times \mathrm{Pa}=\mathrm{Ps} \times \mathrm{Pa}$,

where $S_{\mathrm{L}}$ is the total surface area of level $\mathrm{L}$, and $S_{\mathrm{RL}}$ is the surface area of level $\mathrm{L}$ affected by risk of landslides.

\section{Exposure}

Only residential housing, which is generally terraced or detached, is to be considered as affected elements. Buildings or high-rise residential blocks are not built in the areas dealt with (with the notable exception of the municipality of Benidorm) but in areas that are generally flat and/or near the coast. The mean number of floors confirms this matter (see NFm in Table 2).

The value of these elements only takes into account the gross floor (built-up) area and not the value of land that is not affected by landslides. Taking into account only the cost of constructing the building to calculate the building execution unit cost, the tables of the Institut Valencià de l'Edificació are used (IVE; see https://www.five.es/ productos/herramientas-on-line/modulo-de-edificacion/, last access: 20 May 2021). To do so, the definition of basic building module (BBM; EUR/built-up $\mathrm{m}^{2}$ ) is used, which represents the material cost of implementation per built-up square metre of the reference building, implemented under conventional worksite conditions and circumstances.

The BBM for December 2018 for single-family detached houses of fewer than three floors with an inhabitable surface area of over $70 \mathrm{~m}^{2}$ and with high-quality finishings and fittings is EUR $829 \mathrm{~m}^{-2}$. This value remained practically constant throughout 2018, and even as of 2008 it has been above EUR $800 \mathrm{~m}^{-2}$. Open-plan buildings of three floors or more, up to 80 homes, and an inhabitable surface area of between 45 and $70 \mathrm{~m}^{2}$ are valued at EUR $780 \mathrm{~m}^{-2}$. To a large extent, the homes affected are of the single-family type, so the value of reconstruction has been taken to be constant at EUR $800 \mathrm{~m}^{-2}$. 
Table 4. Probability of occurrence and associated hazard by susceptibility level.

\begin{tabular}{llrrrrr}
\hline Class & $\begin{array}{l}\text { Level } \\
(\mathrm{L})\end{array}$ & $\begin{array}{r}\text { Level surface } \\
\text { area }\left(S_{\mathrm{L}}, \mathrm{ha}\right)\end{array}$ & $\begin{array}{r}\text { Risk surface } \\
\text { area }\left(S_{\mathrm{RL}}, \mathrm{ha}\right)\end{array}$ & $\begin{array}{r}\text { Spatial probability } \\
(\mathrm{Ps})\end{array}$ & $\begin{array}{r}\text { Temporal probability } \\
(\mathrm{Pa})\end{array}$ & $\begin{array}{r}\text { Hazard } \\
(H)\end{array}$ \\
\hline 1 & Very low & 32923.6 & 0 & 0 & - & 0 \\
2 & Low & 22461.0 & 0 & 0 & - & 0 \\
3 & Medium & 43303.9 & 25529 & 0.0005895 & 0.4 & 0.00024 \\
4 & High & 21878.2 & 233675 & 0.0106807 & 0.4 & 0.00427 \\
5 & Very high & 12573.1 & 406913 & 0.0323637 & 0.4 & 0.01295 \\
\hline Total & 133139.8 & 666120 & & \\
\hline
\end{tabular}

The value for reconstructing each cadastral parcel is calculated according to Eq. (14), without taking into account the value of the land.

$$
E_{\mathrm{CP}}(\mathrm{EUR})=\operatorname{GFA}\left(\mathrm{m}^{2}\right) \times \mathrm{BBM}\left(\mathrm{EUR} \mathrm{m}^{-2}\right)
$$

\section{Vulnerability}

In order to determine landslide magnitude (LM) in a geographical area, it is crucial to create a landslide inventory to know the main landslide types, landslide morphometric parameters, landslide velocity and observed damage. These data are not provided by the available landslide databases such as BD-MOVES and COPUT.

In the La Marina area, the predominant failure mechanism for shallow slides is along the existing dip planes of the Cretaceous limestone geological formations. According to Fell (1994), these landslides are defined as small landslides. The shallow slides occurring in the study area are rapid landslides, according to the velocity scale proposed by Cruden and Varnes (1996), with a typical velocity ranging from $1.8 \mathrm{mh}^{-1}$ to $3 \mathrm{mmin}^{-1}$. In La Marina, damage or loss caused by past landslides is poorly documented and this is a major constraint in drawing up vulnerability curves. However, field observations have shown that shallow slides that have occurred in the study area did not have enough energy to completely destroy a building. Typical damage produced by shallow slides in the study area is shown by cracks opening up in the buildings' walls. This type of damage caused by landslides in buildings is classified by Leone (1996) at level III (from I to V), which corresponds to a structural damage of $0.4-0.6$ on a scale ranging from 0 to 1 . Taking into account the previous example and the fact that shallow slide characteristics in the study zone do not vary too much in terms of affected area, depth of the slip surface, velocity, volume and typical damage, we assumed a single fixed value for LM (in accordance with the level of susceptibility). Therefore, the LM was assumed to be 0.6 for the area of study on a heuristic scale ranging from 0 to 1 (Silva and Pereira, 2014) (see Table 5).

The other factor to evaluate the final vulnerability, FV, is to estimate the considered residential buildings' resistance (BR) taking into account the type, materials, age and height
Table 5. Vulnerability related to the number of floors.

\begin{tabular}{lrrr}
\hline $\begin{array}{l}\text { Number of } \\
\text { floors } \\
(\mathrm{NF})\end{array}$ & $\begin{array}{r}\text { Landslide } \\
\text { magnitude } \\
(\mathrm{LM})\end{array}$ & $\begin{array}{r}\text { Building } \\
\text { resistance } \\
(\mathrm{BR})\end{array}$ & $\begin{array}{r}\text { Final } \\
\text { vulnerability } \\
(\mathrm{FV})\end{array}$ \\
\hline$>8$ & 0.6 & $30 \%$ & 0.42 \\
$8-4$ & 0.6 & $20 \%$ & 0.48 \\
$4-2$ & 0.6 & $10 \%$ & 0.54 \\
$<2$ & 0.6 & $0 \%$ & 0.6 \\
\hline
\end{tabular}

of the building (Kappes et al., 2012). Within the zone under study, the construction techniques, materials used (mainly concrete), and structure are quite similar and are considered to be sufficiently resistant with a generally good state of conservation seen in the buildings. The biggest difference one can find is in the mean number of floors for each building, though the type of home affected has a low number on average (see NFm in Table 2) with not very significant variations.

Papathoma-Köhle et al. (2017) identify a list of indicators for one particular kind of landslide (debris flow) physical vulnerability assessment of buildings. One of them, the height of the building, directly influences the degree of loss. In accordance with Papathoma-Köhle et al., the higher the building, the fewer the expected losses, so a greater BR is considered in these cases (Table 5).

Equation (15) enables the final vulnerability FV to be calculated, in which the BR depends solely on the number of floors NF, and Table 5 gives the values obtained by applying it.

$\mathrm{FV}=\mathrm{LM} \times\left(1-\mathrm{BR}_{\mathrm{NF}}\right)$

\section{Risk}

The final calculation of risk for each cadastral parcel is the result of applying Eq. (3). Thus, in accordance with the equations shown above, the final expression for the calculation of 
the risk value for each $\mathrm{CP}$ is

$$
\begin{aligned}
\mathrm{RV}_{\mathrm{CP}}(\mathrm{EUR})= & \left(\frac{S_{\mathrm{RL}}}{S_{\mathrm{L}}} \times \mathrm{Pa}\right) \times(\mathrm{GFA} \times \mathrm{BBM}) \\
& \times\left[\mathrm{LM} \times\left(1-\mathrm{BR}_{\mathrm{NF}}\right)\right]
\end{aligned}
$$

As a final reflection on the application of this or any other method for calculating risk, it should be noted that there is some difficulty in obtaining precise results due to the lack of official data and specific, up-to-date studies in the sphere being studied. Some of these procedures are based on data that are not very exact and even on subjective evaluations, which means some error must be assumed in the results obtained, though this does not invalidate the objectives or the validity of the index originally proposed in our study. For this reason, the global calculation of Eq. (16) has been carried out using the main factors without including ones considered to be less relevant.

\subsection{Risk curve and trend}

The year the temporal series begin is determined in Spain and in the Valencia Community region as 1960, which marked the start of tourism expansion on the Mediterranean coast. The year approximately coincides with when the Act on Centres and Zones of National Tourist Interest (Ley 197/1963 sobre Centros y Zonas de Interés Turístico Nacional) was passed (year 1963), which notably fostered residential construction in coastal areas without taking into account geological risks.

As has been mentioned, to study the evolution of risk, the proposal is to use a complete analysis of the temporal series of the risk ratio value (RR) as the basis. Indeed, the shape of the $\operatorname{RR}(y)$ curve, as well as the behaviour of the two annual series of $\operatorname{GFA}(y)$ and $\operatorname{RV}(y)$, enables the characteristics of the evolution of risk to be established for the entire period.

When the $\operatorname{RR}(y)$ has been calculated, its three singular points are extracted to define the straight lines and calculate their slope via Eq. (10). Specifically, the mean points of the curve were used for the two different periods that include the decades 1960-1969, 1980-1989 and 2000-2009 for a time interval of 20 years. The slopes calculated have been called $m R R$ Lo for the lower (earlier) period (1960s and 1980s) and $m R R H i$ for the higher (later) period (1980s and 2000s).

The first period analysed explains the historical evolution, marking the beginning of the trend, which is why the mean points have been selected from the 1960s and 1980s. For the second period, the decades of the 1980s and 2000s were used. This period acts as a reference for the substantial change in land policy, which should have brought about a clear change in trend. Indeed, it was in the 1990s that the first official study on the risk of landslides appeared (COPUT, 1998). Such work continued with legislative activity that fostered the prevention of natural or induced risk.

\section{Results}

The values of these indicators calculated for the 50 municipalities that make up La Marina are shown in Table 6, accompanied by their interval of variation. A series of annual values were calculated for the 50 municipalities of La Marina area as a whole. The total values for the built-up area (GFA) and risk (RV) are shown in Table 6. The mean values are listed in the same table, as well as their interval of variation of the global indicators in the previous Table 2.

The values of these indicators can be explained logically and are subsequently used to classify the municipalities via a cluster analysis. On drawing up the graphs, the ratios between the total values of GFA and RV from Table 6 were used, which is approximately $8: 1$ (GFA : RV).

As a result of the analysis of the RR, GFA and RV graphs (see the available research data), some interesting behaviour can be found. The comparative graphs of GFA and RV are particularly useful. In general, a marked stability can be seen in the final stretch of the last 10 years, possibly caused by the slowdown in construction after the 2008 crisis. This enables us to affirm that acquisition of residential land with low risk has not been exhausted.

The annual risk peak values are also seen to appear usually after the construction peaks, or at least they are seen very clearly in municipalities with the greatest construction activity. Recalling the possible causes for this situation (listed in Sect. 2.3), this may be due to the fact that after an intense construction period the last parcels to be allotted are usually in zones of greater risk, since those of lesser risk have been allotted first. However, in municipalities with less construction, the construction peaks are more synchronised and even appear before the risk peaks.

Lastly, there is no synchronisation found between the different curves in neighbouring municipalities. Nevertheless, a few behavioural patterns have been obtained in the geographic area under study. Hence, as explained in Sect. 2.3 for the so-called internal synchronisation, the most probable cause should be sought in the differing land management and not in geomorphological or random causes.

Figure 6 shows the evolution of two neighbouring coastal municipalities that represent those with greatest residential construction with a slope close to the average, but which have very different characteristics in assuming risk. They are Calpe (also known as Calp) and Altea (see locations in Figs. 3 and 4 ) - the former with $\mathrm{RR}=79.8$ and the latter with $\mathrm{RR}=463.3$.

Calpe is a mountainous coastal municipality with a high construction rate but a clearly low risk, with a lower risk than the average according to Fig. 6a. In terms of cumulative value, Fig. $6 \mathrm{~b}$ also shows the construction as being more significant than risk, with a sharper slope for the former. Figure 6c shows there is an early stage in the 1970s with a risk peak, which then gradually falls. The RR indicator is very low and everything seems to indicate suitable manage- 

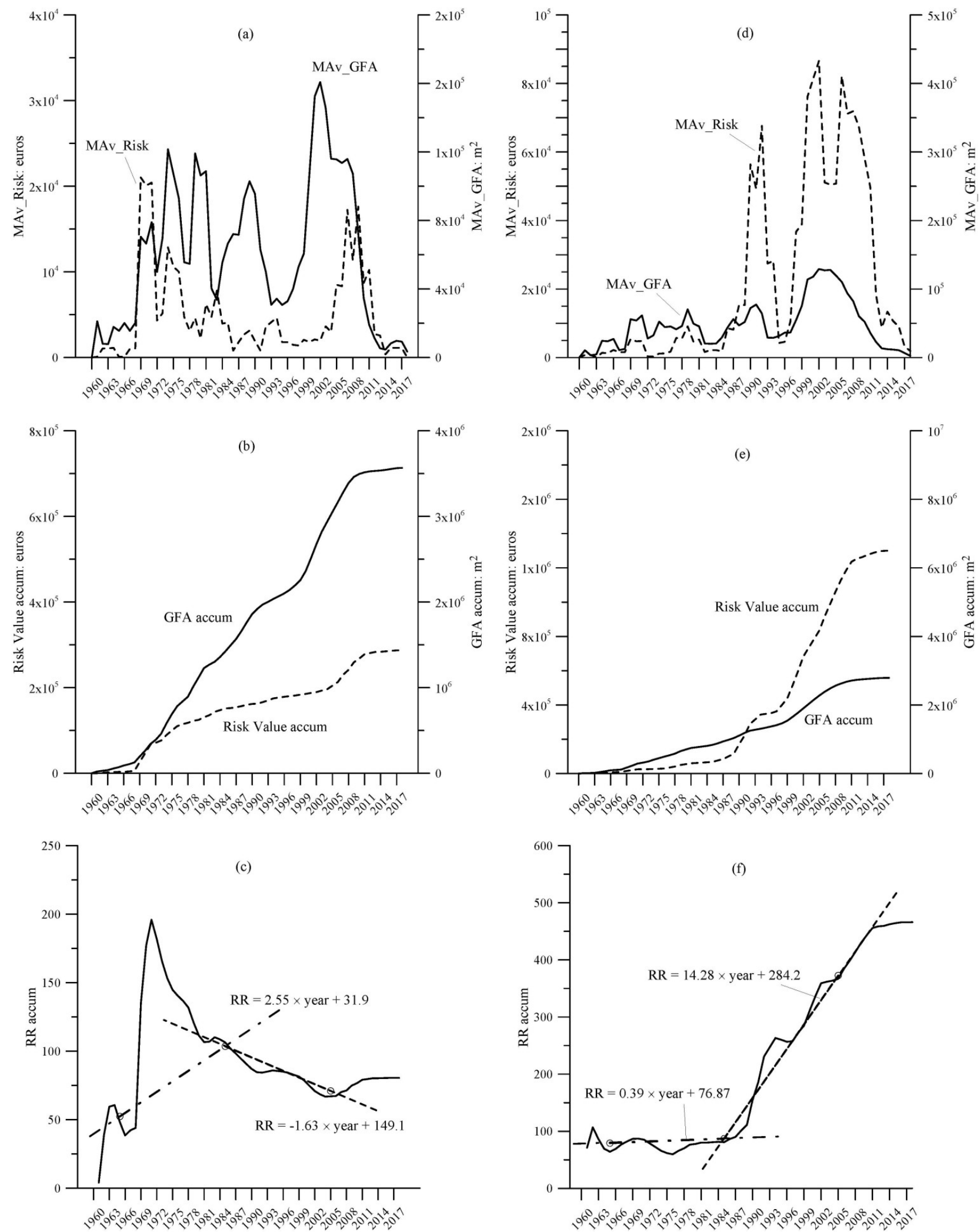

Figure 6. Evolution of the annual series of GFA, RV and RR in the municipalities of Calpe (a-c) and Altea (d-f). 
Table 6. Total values and global indicators per municipality. For indicators, means and variation intervals.

\begin{tabular}{lrlr}
\hline Name & Value & Name & Value \\
\hline Total GFA $\left(\mathrm{m}^{2}\right)$ & 41642352 & Total risk value, RV (EUR) & 5013178 \\
Total risk ratio, RRt & $192.5[0.21-869.3]$ & Dhc $(\mathrm{m})$ & $1490.1[95-3954]$ \\
Mean RR, RRm & $208.5[0.3-988]$ & Dc $(\mathrm{m})$ & $8728.1[1047-19466]$ \\
Mean risk, RVm (EUR) & $2154.7[31-23252]$ & SLm $\left(^{\circ}\right)$ & $16.23[9.8-24.6]$ \\
NFm & $2.09[1.41-5.85]$ & SpGFA $\left(\mathrm{m}^{2} \mathrm{~km}^{-2}\right.$ of UAD) & $26643[470-170659]$ \\
NFmr & $1.87[1.07-5.95]$ & SpRV $\left(\right.$ EUR km$^{-2}$ of UAD) & $3388[11-37412]$ \\
mRR Lo $\left({ }^{\circ}\right)$ & $41.5[83.7 \sim-89.2]$ & mRR Hi $\left({ }^{\circ}\right)$ & $16.9[86.5 \sim-87.8]$ \\
\hline
\end{tabular}

ment over the last 20 years, taking on a comparatively low risk. This pattern is similar to "Suitable management" line of Fig. 1.

In Altea, on the other hand, a greater risk is seen to be assumed in the second half of the series, which is above average (Fig. 6d). Moreover, Fig. 6e shows risk more significantly than construction. Figure $6 \mathrm{f}$ indicates an appropriate beginning for the RR value, but later the relative risk grows. As the indicator value is very high, it can be concluded that this municipality's management should clearly be revised, with a change in trend sought. In both cases we can see risk peaks that come after their corresponding construction peaks. This pattern is similar to "Improvable management" line of Fig. 1.

The possible explanation could be that the plots at greatest risk of landslide begin to be used at a greater pace once the best plots have been occupied following a period of intensive building activity. In other words, it is possible that when suitable plots become scarce, the next buildings are constructed in a worse location and thus a greater risk is taken on.

For the other municipalities, a similar criterion has been followed. High RR values and a straight line with an increasing trend in the second half of the period point to a necessary revision of the protocols in granting construction licences, in view of the growing risk assumed. On the other hand, RR values lower than the average coupled with a decreasing trend indicate a lowering risk and improved land management.

To conclude, Fig. 7 shows the joint evolution of the whole La Marina area (excluding Altea and Benitachell due to the bias they would introduce). Figure 7a shows continual growth in construction and risk almost simultaneously, indicating a clear similarity with the curve pattern shown in Fig. 1 in the three intervals. These curves show a marked jump in the decade of 2000 , coinciding with a period of clear economic boom associated with intense construction activity (known as the "Spanish property bubble" from 1998 to 2008). Finally, Fig. 7b shows fast growth in risk during the first part of the period under consideration, levelling out and becoming comparable to the growth in residential area in the second part of this period. To sum up, no generalised drop is seen in the risk growth rate, so it is hoped that in coming years the urban development regulations in force will end up serving their purpose.

\section{Discussion}

The analysis of the graphs for municipalities is very revealing in learning the effectiveness of their management in lowering the risk of landslides. However, it is important to observe how the municipalities studied are organised and what type of association there may be among them. To do so, a cluster analysis was applied in order to determine the types of groupings that can be found in the area being studied. This type of analysis is a tool that has widely shown its usefulness in grouping urban areas by means of indicators (Huang et al., 2007; Stewart and Janssen, 2014; Goerlich et al., 2017).

The variables to be included in the cluster analysis as explanatory variables were the indicators for each municipality in keeping with Table 6 . They are variables for the period from 1960 until today. However, some of them were discarded a priori. Firstly, this includes the mean number of floors NFm, as there is little variability in this. The mean distance to the historical centre, Dhc, is intended to be a measurement of residential expansion, but it is excessively related to the size of municipality and the location of its historical centre, so that it was also used little. Lastly, mRR Lo was not considered as it is not a main variable and behaves as secondary in the current evolution of risk.

Hence, the variables initially selected for the cluster analysis were mean slope SLm, mRR Hi, SpGFA, Dc, SpRV, RRt and $R R m$, previously standardised. Nevertheless, on carrying out an analysis of prior correlations to avoid variables that do not explain variance as a whole so much, it was found that SpGFA has a very strong linear relationship with the variables SLm, Dc, RRm and SpRV. This means that the rate of construction increases in flat and coastal areas, leading to less risk. Thus, it was decided to eliminate this group of variables from the cluster analysis.

Finally, the analysis was carried out only with the following indicators: the rate of built-up area SpGFA (in $\mathrm{m}^{2} \mathrm{~km}^{-2}$ of UAD), the total risk ratio RRt (EUR per $1000 \mathrm{~m}^{2}$ of GFA) and the final section of slope of the straight trend line $\mathrm{mRR}$ Hi $\left({ }^{\circ}\right)$. These indicators have proven to be sufficiently explanatory variables to be able to establish groups with homogeneous characteristics. In this analysis, all hierarchical methods were tested with different numbers of clusters. 

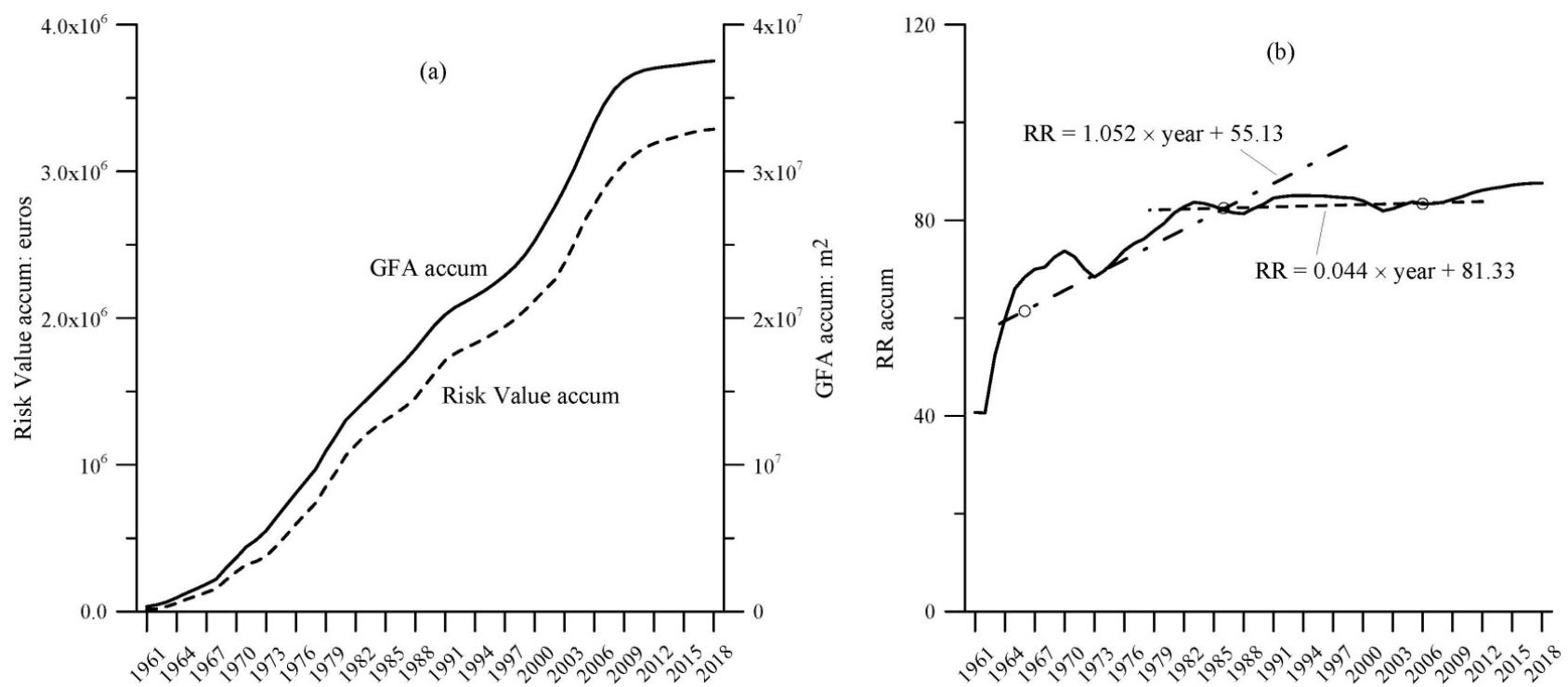

Figure 7. Evolution of the annual series of GFA, RV and RR for the La Marina area.

Ward's method and the Manhattan distance gave the best results. Various attempts were made to find the optimum cluster number of 10 and seeking to differentiate two municipalities with clearly different behaviour: Calpe and Benidorm. Finally a solution was chosen with the greatest number of clusters in order to isolate these unique cases, with 14 in total.

The centroids of the 14 clusters have been organised into four sets - A, B, C and D (from smallest to biggest in magnitude) - according to the percentile values (90th, 60th, 30th and 0th) of the three variables chosen for the analysis (see Table 7). These limits thus established are particularly intended to restrict the upper values of the series ( $>60$ th percentile in A and B). It is thus possible to more clearly highlight the cases that should be addressed in order to manage risks properly. Four types of evaluation for risk building management have been defined for the final curve section value (mRR Hi).

Each of these classes is defined as the result of a new grouping into four clusters for each variable. Table 8 shows the cluster results organised by levels and includes two indicators that provide information relevant to the established clusters. Those two indicators are the mean slope (SLm in degrees) and the specific risk rate (SpRV in EUR $\mathrm{km}^{-2}$ ), previously defined in Table 2 . Table 9 explains each cluster's most relevant characteristics and the municipalities within each of them; if the trend is different for the first section, then the name of the municipality is marked at the end with an asterisk $\left(^{*}\right)$.

As can be seen in Tables 8 and 9, the municipalities with high and very high RR have been differentiated in italics. This situation only occurs with municipalities with a high rate of construction in zones at risk, or in inland too, with very mountainous municipalities where residential buildings are positioned more easily in risk zones, leading to a higher RR. In municipalities with improvable management (BBA, DAA and DBB cluster codes), these high RR values seem to be due to the fact they have been taking on higher risk rates over the last 20 years than in the rest of the historical series. On the other hand, if there is suitable management (only DAD cluster code), these are municipalities that took on greater risks in their first 30 years than they currently do.

Table 9 is shown in map form in Fig. 8. These maps show the municipal distribution of the groups obtained by means of the cluster analysis, as well as their specific risk values (SpRV).

Based on the results obtained, it is seen that many of the municipalities with suitable management today began with overexposure of residential construction in risk zones (marked with "*") in the early decades of the series. This is also seen in the Fig. 1 (Suitable management line) or in the fact that the mRR Lo value exceeds the mRR Hi value. This is logical because during the initial period the protection policies were not so developed. Taking advantage of this lack of control, together with the urban development initiative proposed by tourism legislation, it was possible to construct a greater number of buildings in unsuitable areas.

In the maps in Fig. 8, the municipalities of cluster BBA (Altea and Benitachell) clearly stand out (see location in Fig. 4), where a growing occupation of risk zones can be seen. Indeed, according to Table 8, this cluster has the highest $R R$ value of all the municipalities in groups Axx, Bxx and $\mathrm{Cxx}$, as well as its SpRV and the clearest upward trend. These are therefore the clearest examples of coastal municipalities that should review their criteria for considering land as apt for urban development. Both municipalities are in the process of reviewing their municipal approaches, since in their 
Table 7. Centroid classification values.

\begin{tabular}{lllrr|rl}
\hline \multirow{2}{*}{ Percentile } & Level & Code & SpGFA $\times 1000$ & RRt & mRR high & Type \\
\hline 100th-90th & Very high & A & $170.7-131.7$ & $821-626$ & $86-80$ & Very improvable \\
90th-60th & High & B & $131.7-20.8$ & $626-163$ & $80-48$ & Improvable \\
60th-30th & Low & C & $20.8-4.5$ & $163-88$ & +48 to -40 & Reviewable \\
30th-0th & Very low & D & $4.5-0.9$ & $88-0$ & -40 to -72 & Suitable \\
\hline
\end{tabular}

(a)

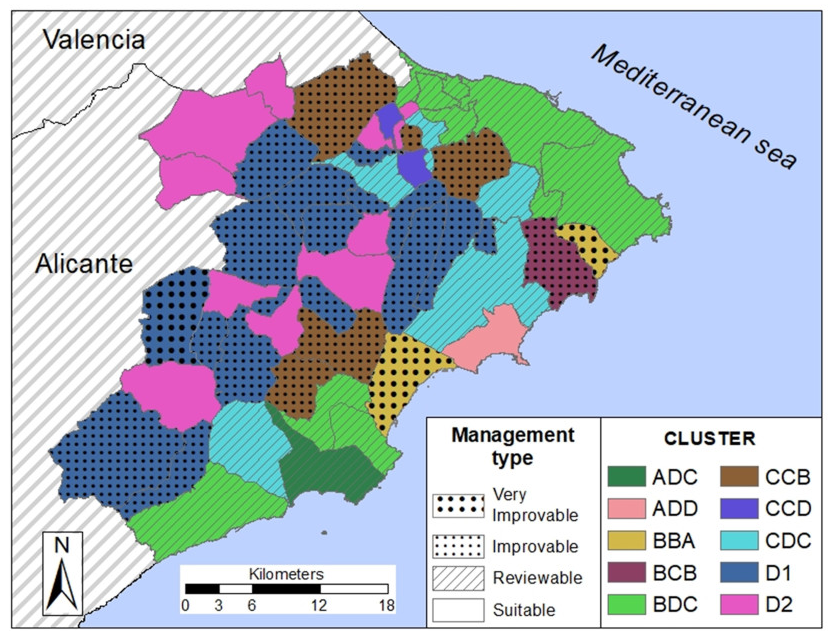

(b)

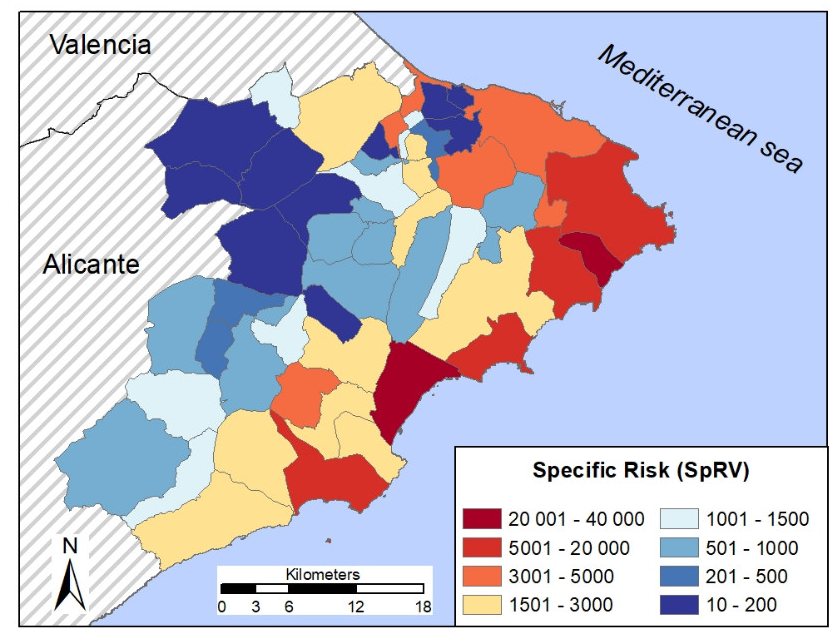

Figure 8. Map of La Marina: (a) with cluster groups*; (b) with the SpRV value.

* D1 clusters: DAA, DBB and DDB; D2 clusters: DAD, DBD and DCD.

previous plans established in the aforementioned first period there were no limits established as regards use based on geological risks.

At the other extreme, there are the mountainous municipalities in groups Dxx (see the maps in Fig. 8) with a high mean slope $\left(>17^{\circ}\right)$. Their location can be clearly seen in the inland strip with broad unstable areas where it is more probable for construction to occur in them. This seems to be the reason why this group has many municipalities with a high RR value, sometimes burdened with this since the beginning of the series due to the effect of homes in the urban hub itself. Furthermore, since these are municipalities with low populations (under 5000 inhabitants), they do not usually have the means to draw up land regulation plans or the technical staff to update them.

Perhaps cluster DDA (Confrides; see location in Fig. 4) is the paradigm among these mountainous municipalities, since it has the second lowest construction rate but a high RR and a growing trend towards risk. It is also the one with the parcels furthest from the coast. It does not have land planning, and according to COPUT (1998) it is one of the municipalities with the greatest density of landslides per unit of area in $\mathrm{La}$ Marina. Although this does not affect a significant number of homes in absolute values, in these conditions an improve- ment in the trend values and risk indicators would seem to be far off. Indeed, this is a singular case in which the municipality has not expressed urban development intentions in any of the three previous periods but will necessarily have to adapt to the land planning regulations in force.

\section{Conclusions}

As a final reflection, it would seem reasonable to think that studies on the mechanics and distribution of landslides, the growth in information about behaviour of the ground, the restrictions imposed on residential expansion, etc., should progressively improve the effectiveness in tackling the risks. However, it has been shown that not all municipalities are capable of reducing the incidence of these risks over time and that, according to Fig. 8, this incidence is still generally high. So why is this happening?

In Sect. 2.1, three possible hypotheses have been put forward to explain this situation. Firstly, the analysis cluster does not enable a direct relationship to be seen between the land's geomorphological characteristics (mainly the mean slope SLm) and the variation in risk. In other words, there are contradictory cases. The same could be said about municipalities with a greater or lesser volume of construction, 
Table 8. Cluster centroids and their levels. Organised from A (max) to D (min) according to Table 7.

\begin{tabular}{|c|c|c|c|c|c|c|c|c|c|}
\hline \multicolumn{8}{|c|}{ Cluster centroids } & \multicolumn{2}{|c|}{ Other indicators (mean) } \\
\hline $\begin{array}{l}\text { Cluster } \\
\text { number }\end{array}$ & SpGFA $\times 1000$ & Level 1 & RRt & Level 2 & mRR Hi & Level 3 & $\begin{array}{l}\text { Cluster } \\
\text { CODE }\end{array}$ & SLm & $\mathrm{SpRV} \times 1000$ \\
\hline 1 & 170.7 & A & 86 & $\mathrm{D}$ & 38 & $\mathrm{C}$ & $\mathrm{ADC}$ & 11.3 & 14.62 \\
\hline 2 & 152.3 & $\mathrm{~A}$ & 80 & $\mathrm{D}$ & -58 & $\mathrm{D}$ & $\mathrm{ADD}$ & 13.8 & 12.15 \\
\hline 3 & 69.5 & $\mathrm{~B}$ & 500 & B & 86 & A & BBA & 14.5 & 34.34 \\
\hline 4 & 62.7 & $\mathrm{~B}$ & 146 & $\mathrm{C}$ & 53 & $\mathrm{~B}$ & $\mathrm{BCB}$ & 10.7 & 9.17 \\
\hline 5 & 81.4 & $\mathrm{~B}$ & 39 & $\mathrm{D}$ & -13 & $\mathrm{C}$ & $\mathrm{BDC}$ & 10.8 & 3.74 \\
\hline 6 & 20.9 & $\mathrm{C}$ & 72 & $\mathrm{D}$ & -1 & $\mathrm{C}$ & $\mathrm{CDC}$ & 6.1 & 0.01 \\
\hline 7 & 20.0 & $\mathrm{C}$ & 164 & $\mathrm{C}$ & -65 & $\mathrm{D}$ & $\mathrm{CCD}$ & 14.2 & 1.96 \\
\hline 8 & 18.6 & $\mathrm{C}$ & 154 & $\mathrm{C}$ & 71 & B & $\mathrm{CCB}$ & 14.3 & 2.81 \\
\hline 9 & 0.9 & $\mathrm{D}$ & 679 & A & 82 & A & DAA & $22.1^{*}$ & 0.94 \\
\hline 10 & 3.5 & $\mathrm{D}$ & 296 & B & 77 & B & DBB & $19.6^{*}$ & 0.93 \\
\hline 11 & 4.4 & $\mathrm{D}$ & 88 & $\mathrm{D}$ & 54 & B & DDB & $18.8^{*}$ & 0.41 \\
\hline 12 & 1.6 & $\mathrm{D}$ & 821 & A & -72 & D & DAD & $23.2^{*}$ & 1.36 \\
\hline 13 & 2.5 & $\mathrm{D}$ & 324 & B & -66 & $\mathrm{D}$ & DBD & $22.3^{*}$ & 0.79 \\
\hline 14 & 4.5 & $\mathrm{D}$ & 105 & $\mathrm{C}$ & -39 & $\mathrm{D}$ & DCD & $16.7^{*}$ & 0.52 \\
\hline
\end{tabular}

* Inland hilly areas $\left(\mathrm{SLm} \geq 17^{\circ}\right)$.

Table 9. List of clusters with their characteristics and municipalities assigned. Grouped by intensity construction ratio (SpGFA) from high to low.

\begin{tabular}{|c|c|c|c|c|}
\hline SpGFA & $\begin{array}{l}\text { Cluster } \\
\text { CODE }\end{array}$ & Other remarkable characteristics & $\begin{array}{l}\text { Risk building } \\
\text { management }\end{array}$ & Municipalities \\
\hline Very & $\mathrm{ADC}$ & Very low RR & Reviewable & Benidorm* \\
\hline high & ADD & Very low RR and trend & Suitable & Calpe* \\
\hline \multirow{3}{*}{ High } & $\mathrm{BBA}$ & High RR and very high growth trend & Very improvable & Altea, Benitachell \\
\hline & $\mathrm{BCB}$ & High trend & Improvable & Teulada \\
\hline & $\mathrm{BDC}$ & Very low RR & Reviewable & $\begin{array}{l}\text { L'Alfàs del Pí, Xabia*, La Nucía*, } \\
\text { Denia*, Villajoyosa, Ondara, El Verger }\end{array}$ \\
\hline \multirow{3}{*}{ Low } & $\mathrm{CDC}$ & Very low RR & Reviewable & $\begin{array}{l}\text { Beniarbeig, Benidoleig*, Benissa*, } \\
\text { Finestrat*, Gata de Gorgos*, Orba* }\end{array}$ \\
\hline & CCD & Very low growth trend & Suitable & Benidoleig*, Ràfol d’Almúnia \\
\hline & CCB & High growth trend & Improvable & $\begin{array}{l}\text { Callosa, Polop, Pedreguer, Pego, Sanet } \\
\text { y Negrals }\end{array}$ \\
\hline \multirow{6}{*}{$\begin{array}{l}\text { Very } \\
\text { low }\end{array}$} & DAA & Very high RR and growth trend & Very improvable & Confrides \\
\hline & $\mathrm{DBB}$ & High RR and growth trend & Improvable & $\begin{array}{l}\text { Alcalalí, Benifato, Benigembla, Beni- } \\
\text { mantell, Lliber, Orxeta, Relleu*, Xaló }\end{array}$ \\
\hline & DDB & High growth trend & Improvable & $\begin{array}{l}\text { Bolulla, Castell de Castells, Vall d'Ebo, } \\
\text { Murla, Senija, Tormos, Vall de Laguar, } \\
\text { Xaló }\end{array}$ \\
\hline & DAD & Very high RR; very low trend & Suitable & Castell de Guadalest, Sella* \\
\hline & DBD & Very low trend & Suitable & Adsubia, Beniardá*, Tárbena \\
\hline & DCD & Very low trend & Suitable & $\begin{array}{l}\text { Benimeli*, Vall d'Alcalà*, Parcent*, } \\
\text { Sagra*, Vall de Gallinera* }\end{array}$ \\
\hline
\end{tabular}

* Municipalities with a change in trend from the first part of a series to the second. 
proximity to the coast, etc. Hence, a greater or lesser risk value and a growing or falling trend cannot be attributed to the intrinsic qualities of the municipalities studied. Nor can they be attributed to strictly random factors, since there is coherent behaviour within the clusters analysed.

The above conclusions are bolstered when one considers the lack of temporal correlation found for the data in neighbouring series, together with the existence of global behaviour patterns (see Sect. 2.3). As a result of all of this, the assumption of greater or lesser risk and its temporal evolution seems to be exclusively due to the third hypothesis initially put forward in the aforementioned Sect. 2.1; i.e. land management. In this study, procedures have been proposed that are based on analyses of graphs and risk indicators in order to find trends and behaviours that may subsequently help to improve this land management.

The risk ratio (RR) developed in this article stands out as a robust indicator for directly finding the relationship between residential construction and its associated risk. It is especially useful for coastal municipalities with a high rate of construction, since it differentiates between those that take on a higher risk than those that do not. Nevertheless, in municipalities located in the inland mountainous strip - with a low residential construction density, with a high susceptibility and which do not usually have land planning - the values are also high. In these cases it is not possible to strictly attribute these values to unsuitable management.

In general, it is seen that coastal municipalities are more prone to assume greater specific risk (see Fig. 8), although the pace of growth in risk is lower than for construction. In mountainous municipalities in the inland strip, precisely the opposite happens. Of course there are a fair number of exceptions to this rule, but two coastal municipalities especially stand out, where their great construction intensity is exceeded by the growing pace of occupation of zones at risk. This is group BBA, which includes Altea and Benitachell (the characteristics of Altea have already been specified in Fig. 6). Although their land occupation has not reached the level of very high intensity construction ratio (SpGFA), both municipalities are characteristic for having high SpGFA and RR values, which shows a growing occupation of locations at risk.

Benidorm (ADC cluster) is precisely an example worth highlighting (Fig. 4). It is a coastal municipality that is internationally known as a holiday destination with a notably mountainous profile. It has one of the biggest construction rates in the area, but this has not led to occupation of extensive risk areas, although there is a slight upward trend. It is not surprising, then, that this is the only example of "vertical" construction, where the mean number floors per building (5.85) is significantly greater than in the other municipalities in the study (2.09). Hence, it can be considered a suitable policy if the objective is to provide a greater amount of builtup area in relation to the risk taken $(\mathrm{RR}=86$, found in the 30th percentile).
To sum up, none of the basic risk parameters in any municipality seems to be determined by randomness, and only in the most mountainous ones is it determined by the orographic conditions of the land. Monitoring and restriction of building in risk zones must be applied mainly in the coastal municipalities with a greater rate of construction. Residential construction's avoidance of zones at risk of landslide will depend on the municipal technicians having complete, up-todate information in their urban development regulation planning; in other words, they should have been reviewed in the last decade. Only in this way will it be possible to have objective criteria in order to enforce urban development regulations and their implicit "precautionary principle" in order to guarantee the greatest possible level of protection.

The risks of landslide are a result of human activity itself, and it is also of great human concern to minimise them. The mechanisms for monitoring and control that should be working to reduce them must not be solely the responsibility of the municipality, but also of public bodies of greater hierarchy that may ensure they are applied by using their best resources and regulatory capacity. Tools have been developed in this work to take objective decisions to suitably adapt land management, and this can be extended to other residential areas. Applying them does not guarantee that the problem will be eliminated, but at least it will help alleviate them and act as a guide to solve them.

Data availability. Borders and areas for the municipal territories and the $5 \times 5 \mathrm{~m}$ DEM (digital elevation model) are available on the Spanish Geographic Institute (IGN, 2021; https://centrodedescargas.cnig.es/CentroDescargas/index.jsphttps: //www.ign.es/web/ign/portal). The database for landslides was processed from BD-MOVES, available on the Geological and Mining Institute of Spain (IGME, 2021; http://mapas.igme.es/ gis/rest/services/BasesDatos/IGME_BDMoves_ES/MapServer) and also from the project entitled "Lithology, exploitation of industrial rocks and landslide risk in the Valencia Community", available online on COPUT (Valencia regional government website, http://politicaterritorial.gva.es/documents/ 20551069/169376163/05.1+Litologia+aprovechamiento+

de+rocas+industriales+y+riesgo+de+deslizamiento+en+la+ Comunitat+Valenciana/e5113e77-3ad2-4f5e-89e3-df36337f206b, COPUT, 1998). The information referring to cadastral plots or parcels was obtained from the cadastral mapping available from the Spanish Cadastral Directorate (DGC, 2021; http://www.catastro.minhap.es/webinspire/index.html). The landslide susceptibility map (LSM) with a resolution of $25 \times 25 \mathrm{~m}$ in La Marina can be found in Cantarino et al. (2019). Further information can be made available upon request to the corresponding author.

Author contributions. All authors contributed to conceptualisation, led by IC, who also conducted the formal analysis and initial draft. JSPJ had a leading role on urban planning perspective. MAC contributed to validation and data visualisation. VMI critically re- 
viewed the paper and contributed to the preparation of the final version.

Competing interests. The authors declare that they have no conflict of interest.

Acknowledgements. Authors acknowledge funding from Department of Geological and Geotechnical Engineering, Universitat Politècnica de València.

Review statement. This paper was edited by Paola Reichenbach and reviewed by Eleftheria Poyiadji and two anonymous referees.

\section{References}

Birkmann, J., Garschagen, M., and Setiadi, N.: New challenges for adaptive urban governance in highly dynamic environments: Revisiting planning systems and tools for adaptive and strategic planning, Urban Climate, 7, 115-133, https://doi.org/10.1016/j.uclim.2014.01.006, 2014.

Cantarino, I., Torrijo, F. J., Palencia, S., and Gielen, E.: Assessing residential building values in Spain for risk analyses - application to the landslide hazard in the Autonomous Community of Valencia, Nat. Hazards Earth Syst. Sci., 14, 3015-3030, https://doi.org/10.5194/nhess-14-3015-2014, 2014.

Cantarino, I., Carrion, M. A., Goerlich, F., and MartínezIbáñez, V.: A ROC analysis-based classification method for landslide susceptibility maps, Landslides, 16, 265-282, https://doi.org/10.1007/s10346-018-1063-4, 2019.

Cascini, L.: Applicability of landslide susceptibility and hazard zoning at different scales, Eng. Geol., 102, 164-177, https://doi.org/10.1016/j.enggeo.2008.03.016, 2008.

Cascini, L., Bonnard, C., Corominas, J., Jibson, R., and MonteroOlart, J.: Landslide hazard and risk zoning for urban planning and development, in: Landslide Risk Management, Taylor and Francis, London, 209-246, 2005.

COPUT: Litología, aprovechamiento de rocas industriales y riesgo de deslizamiento en la Comunidad Valenciana, Conselleria d'Obres Públiques, Urbanisme i Transports, Valencia, available at: http://politicaterritorial.gva.es/documents/20551069/ 169376163/05.1+Litologia+aprovechamiento+de+rocas+ industriales+y+riesgo+de+deslizamiento+en+la+Comunitat+ Valenciana/e5113e77-3ad2-4f5e-89e3-df36337f206b (last access: 20 May 2021), 1998.

Corominas, J., van Westen, C., Frattini, P., Cascini, L., Malet, J.-P., Fotopoulou, S., Catani, F., Van Den Eeckhaut, M., Mavrouli, O., Agliardi, F., Pitilakis, K., Winter, M. G., Pastor, M., Ferlisi, S., Tofani, V., Hervás, J., and Smith, J. T.: Recommendations for the quantitative analysis of landslide risk, B. Eng. Geol. Environ., 73, 209-263, https://doi.org/10.1007/s10064-013-0538-8, 2014.

Cruden, D. M. and Varnes, D. J.: Landslide types and processes, Spec. Rep. - Natl. Res. Counc. Transp. Res. Board, 247(January 1996), 36-75, available at: https://onlinepubs.trb.org/ Onlinepubs/sr/sr247/sr247-003.pdf (last access: 20 May 2021), 1996.
Dai, F., Lee, C., and Ngai, Y.: Landslide risk assessment and management: an overview, Eng. Geol., 64, 65-87, https://doi.org/10.1016/S0013-7952(01)00093-X, 2002.

EEA - European Environmental Agency: Urban sprawl in Europe: The ignored challenge, Office for Official Publications of the European Communities, Luxembourg, available at: https://www.eea.europa.eu/publications/eea_report_2006_10/ eea_report_10_2006.pdf/view (last access: 20 May 2021), 2006.

Faccini, F., Luino, F., Sacchini, A., Turconi, L., and De Graff, J. V.: Geohydrological hazards and urban development in the Mediterranean area: an example from Genoa (Liguria, Italy), Nat. Hazards Earth Syst. Sci., 15, 2631-2652, https://doi.org/10.5194/nhess-15-2631-2015, 2015.

Fell, R.: Landslide risk assessment and acceptable risk, Can. Geotech. J., 31, 261-272, https://doi.org/10.1139/t94-031, 1994.

Fell, R., Corominas, J., Bonnard, C., Cascini, L., Leroi, E., and Savage, W. Z.: Guidelines for landslide susceptibility, hazard and risk zoning for land use planning, Eng. Geol., 102, 85-98, https://doi.org/10.1016/j.enggeo.2008.03.022, 2008.

Fernández Arce, M., Méndez Ocampo, I., and Muñoz Jiménez, R.: Impacto de los deslizamientos y asentamientos del suelo en el cantón Moravia, Rev. En Torno a la Prevención, 17, 7-16, available at: http://revistaentorno.desastres.hn/pdf/spa/doc1701/ doc1701-contenido.pdf (last access: 20 May 2021), 2016.

Gallina, V., Torresan, S., Critto, A., Sperotto, A., Glade, T., and Marcomini, A.: A review of multi-risk methodologies for natural hazards: Consequences and challenges for a climate change impact assessment, J. Environ. Manage., 168, 123-132, https://doi.org/10.1016/j.jenvman.2015.11.011, 2016.

Gariano, S. L. and Guzzetti, F.: Landslides in a changing climate, Earth-Sci. Rev., 162, 227-252, https://doi.org/10.1016/j.earscirev.2016.08.011, 2016.

Geological and Mining Institute of Spain (IGME): BDMOVES (Spanish Landslide Database), available at: http://mapas.igme.es/gis/rest/services/BasesDatos/IGME_ BDMoves_ES/MapServer, last access: 20 May 2021.

Glade, T.: Vulnerability assessment in landslide risk analysis, Die Erde, 134, 123-146, available at: https://www.researchgate.net/profile/Thomas_Glade/publication, /279555131_Vulnerability_assessment_in_landslide_risk, _analysis_Vulnerabilitatsbewertung_in_der_Naturrisikoanalyse, _gravitativer_Massenbewegungen/links/56c5e8e108ae03b93dd, 9c296/Vulnerability-assessment-in-landslide-risk-analysisVulnerabilitaetsbewertung-in-der-Naturrisikoanalysegravitativer-Massenbewegungen.pdf (last access: 20 May 2021), 2003.

Glade, T., Anderson, M., and Crozier, M. J.: Landslide Hazard and Risk, edited by: Glade, T., Anderson, M., and Crozier, M. J., John Wiley and Sons, Ltd, Chichester, West Sussex, England, 2005.

Goerlich Gisbert, F. J., Cantarino Martí, I., and Gielen, E.: Clustering cities through urban metrics analysis, J. Urban Design, 22, 689-708, https://doi.org/10.1080/13574809.2017.1305882, 2017.

Gough, J.: Perceptions of risk from natural hazards in two remote New Zealand communities, Australas, J. Disaster Trauma Stud., 2, available at: http://rauma.massey.ac.nz/issues/2000-2/gough. htm (last access: 20 May 2021), 2000. 
Hamma, W. and Petrişor, A.-I.: Urbanization and risks: case of Bejaia city in Algeria, Human Geographies, 12, 97-114, https://doi.org/10.5719/hgeo.2018.121.6, 2018.

Hervas, J.: El inventario de movimientos de ladera de España ALISSA: Metodología y análisis preliminar, in IX Simposio Nacional sobre Taludes y Laderas Inestables, pp. 629639, IX Simposio nacional sobre taludes y laderas inestables - Taludes 2017, Santander, Spain, available at: http://congress. cimne.com/simposiotaludes2017/frontal/doc/Ebook.pdf (last access: 20 May 2021), 2017.

Huang, J., Lu, X. X., and Sellers, J. M.: A global comparative analysis of urban form: Applying spatial metrics and remote sensing, Landscape Urban Plan., 82, 184-197, https://doi.org/10.1016/j.landurbplan.2007.02.010, 2007.

Kappes, M. S., Papathoma-Köhle, M., and Keiler, M.: Assessing physical vulnerability for multi-hazards using an indicator-based methodology, Appl. Geogr., 32, 577-590, https://doi.org/10.1016/j.apgeog.2011.07.002, 2012.

Katsigianni, X. and Pavlos-Marinos, D.: The interrelation between spatial planning policies and safety in the multi-risk insular setting of Santorini, in Cities and regions in a changing Europe: challenges and prospects, 54th Colloquium of the Association de Science Régionale de Langue Française (ASRDLF)/15th conference of the Greek Section of the European Regional Science Association, Athens, 1-18, available at: https://www. researchgate.net/publication/319530894_The_interrelation_ between_spatial_planning_policies_and_safety_in_the_ multi-risk_insular_setting_of_Santorini\#fullTextFileContent (last access: 20 May 2021), 2017.

Lee, E. M.: Landslide risk assessment: the challenge of estimating the probability of landsliding, Q. J. Eng. Geol. Hydroge., 42, 445-458, https://doi.org/10.1144/1470-9236/08-007, 2009.

Lee, E. M. and Jones, D. K. C.: Landslide risk assessment, Thomas Telford Publishing, London, 2004.

Lee, J., Lee, D. K., Kil, S.-H., and Kim, H. G.: Riskbased analysis of monitoring time intervals for landslide prevention, Nat. Hazards Earth Syst. Sci. Discuss. [preprint], https://doi.org/10.5194/nhess-2017-356, 2017.

Leone, F.: Concept de vulnérabilité appliqué à l'évaluation des risques générés par les phénomènes de mouvements de terrain, Université Joseph Fourier, Grenoble, 1, 1996.

Macintosh, A.: Coastal climate hazards and urban planning: how planning responses can lead to maladaptation, Mitig. Adapt. Strat. Gl., 18, 1035-1055, https://doi.org/10.1007/s11027-0129406-2, 2013.

Malvárez García, G., Pollard, J., and Domínguez Rodríguez, R.: The Planning and Practice of Coastal Zone Management in Southern Spain, J. Sustain. Tour., 11, 204-223, https://doi.org/10.1080/09669580308667203, 2003.

Di Martire, D., De Rosa, M., Pesce, V., Santangelo, M. A., and Calcaterra, D.: Landslide hazard and land management in highdensity urban areas of Campania region, Italy, Nat. Hazards Earth Syst. Sci., 12, 905-926, https://doi.org/10.5194/nhess-12905-2012, 2012.
Papathoma-Köhle, M., Gems, B., Sturm, M., and Fuchs, S.: Matrices, curves and indicators: A review of approaches to assess physical vulnerability to debris flows, Earth-Sci. Rev., 171, 272288, https://doi.org/10.1016/j.earscirev.2017.06.007, 2017.

Pardo-García, S. and Mérida-Rodríguez, M.: Physical location factors of metropolitan and rural sprawl: Geostatistical analysis of three Mediterranean areas in Southern Spain, Cities, 79, 178186, https://doi.org/10.1016/j.cities.2018.03.007, 2018.

Peng, S.-H. and Wang, K.: Risk evaluation of geological hazards of mountainous tourist area: a case study of Mengshan, China, Nat. Hazards, 78, 517-529, https://doi.org/10.1007/s11069-0151724-8, 2015.

Renn, O. and Klinke, A.: A Framework of Adaptive Risk Governance for Urban Planning, Sustainability, 5, 2036-2059, https://doi.org/10.3390/su5052036, 2013.

Sandić, C., Abolmasov, B., Marjanović, M., Begović, P., and Jolović, B.: Landslide Disaster and Relief Activities: A Case Study of Urban Area of Doboj City, in: Advancing Culture of Living with Landslides, Springer International Publishing, Cham, 383-393, 2017.

Silva, M. and Pereira, S.: Assessment of physical vulnerability and potential losses of buildings due to shallow slides, Nat. Hazards, 72, 1029-1050, https://doi.org/10.1007/s11069-014-10524, 2014.

Spanish Cadastral Directorate (DGC): Cadastral data, available at: http://www.catastro.minhap.es/webinspire/index.html, last access: 20 May 2021.

Spanish Geographic Institute (IGN): Spanish Digital Elevation Model, available at: https://centrodedescargas.cnig.es/ CentroDescargas/index.jsphttps://www.ign.es/web/ign/portal, last access: 20 May 2021.

Spanish National Institute of Statistics (INE): Census population data, available at: https://www.ine.es/dyngs/INEbase/es/ categoria.htm?c=Estadistica_P\&cid=1254734710990 (last access 20 May 2021), 2018.

Stewart, T. J. and Janssen, R.: A multiobjective GIS-based land use planning algorithm, Comput. Environ. Urban, 46, 25-34, https://doi.org/10.1016/j.compenvurbsys.2014.04.002, 2014.

de Terán, F.: El problema urbano, Salvat, Barcelona, 1982.

UNDRO: Natural disasters and vulnerability analysis: report of Expert Group Meeting, 9-12 July 1979, United Nations, Geneva, available at: http://digitallibrary.un.org/record/95986 (last access: 20 May 2021), 1979.

Wang, J., Shi, P., Yi, X., Jia, H., and Zhu, L.: The regionalization of urban natural disasters in China, Nat. Hazards, 44, 169-179, https://doi.org/10.1007/s11069-006-9102-1, 2008.

Zhai, G., Li, S., and Chen, J.: Reducing Urban Disaster Risk by Improving Resilience in China from a Planning Perspective, Hum. Ecol. Risk Assess., 21, 1206-1217, https://doi.org/10.1080/10807039.2014.955385, 2015.

Zhou, N. Q. and Zhao, S.: Urbanization process and induced environmental geological hazards in China, Nat. Hazards, 67, 797810, https://doi.org/10.1007/s11069-013-0606-1, 2013. 